\title{
Microprospección arqueológica en Giribaile (Vilches, Jaén). Protocolo de trabajo (1)
}

\author{
Archaeological microsurvey in Giribaile (Vilches, Jaén). Work guideline
}

Luis María Gutiérrez Soler (*)

\section{RESUMEN}

El interés por desarrollar métodos de prospección arqueológica cada vez más rigurosos y precisos constituye el objeto de interés de este protocolo de trabajo. Desde hace décadas se vienen desarrollando estudios experimentales en todo el mundo, especialmente en el Mediterráneo. La microprospección arqueológica está interesada en introducir estos buenos comportamientos metodológicos, como el análisis estadístico de las colecciones de superficie, en la práctica arqueológica española. La búsqueda de unas condiciones de observación lo más homogéneas posible, el control espacial de los sistemas de registro y la explicación de los métodos empleados constituyen la base de esta propuesta centrada en los estudios de sitio. La intervención arqueológica llevada a cabo en 2004-2005 en el oppidum ibérico de Giribaile ilustra los resultados obtenidos en este estudio de caso, permitiendo mejorar el conocimiento de la complejidad interna y la secuencia cronológica del sitio. La microprospección, basada en muestreos arqueológicos sistemáticos, trata de adaptar y mejorar la teoría clásica de la prospección de superficie, basada en registros intensivos, a las condiciones particulares de la investigación.

\footnotetext{
ABSTRACT

We are interested in developing more rigorous and precise survey methods to get a recording protocol. Experimental studies have been developed during decades around the world, especially in the Mediterranean area.

(*) Universidad de Jaén. Centro Andaluz de Arqueología Ibérica. Paraje de Las Lagunillas, s/n. 23071 Jaén. Correo electrónico: 1msoler@ujaen.es

Recibido: 22-VI-2009; aceptado: 14-XII-2009.

(1) El presente trabajo ha contado con la ayuda concedida por la Secretaría de Estado de Universidades e Investigación del Ministerio de Educación y Ciencia (referencia: PR2008-0173), a través de la concesión de una estancia en el Institute of Archaeology de Oxford desde el 1 de noviembre de 2008 hasta el 31 de enero de 2009, dentro del Programa Salvador de Madariaga.
}

It is necessary to introduce these good methodologies, such as the statistic analysis of surface collections, in Spanish archaeological practices. Standardised observations, the spatial control of the recording systems and the explanation of the methods used are very important to obtain good results in current research projects. The archaeological survey that we carried out at the Iberian oppidum of Giribaile in 2004-2005 allowed us to progress in our knowledge of the internal complexity and the chronological sequence of the site and it represents a study case that illustrates some of the possibilities that we hope obtain. The "microsurvey" method, based on systematic archaeological sampling, tries to adapt and improve the classical surface survey theory.

Palabras clave: Arqueología de campo; Arqueología Espacial; Estudio diacrónico; Edad del Hierro/Protohistoria; Alta Edad Media; Andalucía; Termoluminiscencia.

Key words: Field archaeology; Spatial archaeology; Diachronic study; Iron Age/Protohistory; Upper Middle Ages; Andalucia; Thermoluminisce.

\section{INTRODUCCIÓN}

Tal y como apunta T. Banning (2002) en el prólogo de su monografía, después de décadas de llevar a cabo prospecciones arqueológicas con diseños intuitivos, en los años 1960 algunos arqueólogos vinculados a la New Archaeology comenzaron a ser más explícitos a la hora de preparar y explicar sus diseños. Surgieron numerosas publicaciones en las dos décadas siguientes pero, a diferencia de lo que ocurrió con los métodos de excavación, la prospección no recibió un tratamiento similar que se concretara en la elaboración de guías útiles de trabajo. Pese a todo esto, los registros intensivos de superficie se han convertido en una práctica habitual en los proyectos desarrollados por equipos de investigación anglo- 
sajones (estadounidenses, primero, y británicos, más tarde, sobre todo a partir de los 1970) en todo el mundo, incluyendo el ámbito mediterráneo y ofreciendo nuevas oportunidades para tratar la reconstrucción de la historia del poblamiento y el uso de la tierra, especialmente en Grecia e Italia (Bintliff y Snodgrass 1985; Barker 1991: 1-2; Francovich y Patterson 2000). En este sentido, resulta muy significativo observar los resultados estadísticos obtenidos al comparar las primeras prospecciones llevadas a cabo en Grecia con las desarrolladas desde los años $1970 \mathrm{y}$, por extensión, con las prospecciones a gran escala en Italia o, más recientemente, con los proyectos vinculados al estudio del Levante mediterráneo e, incluso, Mesopotamia (Wilkinson 2004a: 57).

El estado de la cuestión sobre la prospección arqueológica en España no parece alejarse mucho del panorama general diseñado por T. Banning. Muestra, además, un déficit importante de trabajos teóricos que aborden directamente los aspectos metodológicos, cuestión que no pasó desapercibida para los equipos británicos que comenzaron a desarrollar proyectos de investigación que incluían campañas de prospección en diferentes territorios a partir de los 1980 y los 1990 (Jones et al. 1985: 126; Keay y Millet 1991: 133). Recientemente, G. Ruiz Zapatero (2004), al realizar un balance sobre los últimos veinte años de Arqueología Espacial en España, pese a establecer los indicadores sobre la madurez alcanzada, subraya la falta de explicaciones acerca de los criterios empleados en el diseño y documentación en muchas de las publicaciones y, especialmente, sobre la escasez de controles de calidad como práctica habitual de la prospección arqueológica.

Es, precisamente, este ámbito el que despierta nuestro interés y en el que venimos actuando como línea prioritaria desde el Centro Andaluz de Arqueología Ibérica interesándonos, especialmente, por el tratamiento de los muestreos arqueológicos, dentro de una tendencia generalizada de reducir las áreas de trabajo para aumentar la intensidad de la prospección.

A principios de los 1990 Shennan (1985: 8) comienza a evaluar las prospecciones no en términos de cantidades de materiales recogidos $o$ por el número de sitios descubiertos, sino a partir de la consideración de los métodos empleados para obtener dichos resultados. En esa línea surgió la preocupación en nuestro grupo de investigación por fijar criterios, lo más objetivos posi- ble, en la práctica de la prospección arqueológica. No se trataba tanto de seguir localizando un número creciente de sitios, ni de continuar recogiendo en ellos cada vez más materiales, sino de controlar los criterios con los que se llevaba a cabo esa recolección y los factores, de todo tipo, que podían influir en el desarrollo del trabajo, asumiendo que la definición de un sitio es, ante todo, un acto de interpretación (Alcock et al. 1994: 138). Debíamos abordar, en definitiva, el siguiente paso en el diseño de una estrategia seria de prospección: establecer protocolos de trabajo válidos para documentar colecciones de materiales $\mathrm{y}$ articular los mecanismos necesarios para la recogida de artefactos.

Esta crisis de crecimiento o pérdida de la inocencia en la planificación y el diseño de los análisis del territorio vino de la mano de una reflexión madura, a partir de los nuevos cuerpos interpretativos y marcos teóricos que llegaban desde el mundo anglosajón, y también de consideraciones de orden práctico, como los problemas surgidos a la hora de revisar los sitios arqueológicos que se habían prospectado hacía años en zonas clásicas de trabajo como la Campiña de Jaén. Así, actualmente un arqueólogo encuentra dificultades a la hora de localizar un yacimiento catalogado tiempo atrás (problema hoy bien resuelto con la utilización de la tecnología GPS). Además, debe enfrentarse a graves deficiencias en las lecturas propuestas, ya que las descripciones literales, normalmente, no contienen valoraciones acerca de los criterios empleados, ni porcentajes sobre las clases de materiales presentes en la superficie del terreno o la manera en que estos se distribuían dentro de un asentamiento. Habitualmente, estas colecciones presentan altas proporciones de piezas inusuales y otras bajas de los ítems más frecuentes, además de una selección por tamaños y por períodos cronológicos (Drennan 1996: 88). $\mathrm{Su}$ análisis resulta de un gran interés para comprender el estado del conocimiento de la cultura material en un momento concreto de la historia de la investigación.

Las colecciones incontroladas, entendiendo por tales aquellas en las que el registro espacial no ha sido suficientemente preciso, representan un grave problema. Obvian la información contextual inherente a la distribución de dichos materiales y la consecuente correlación entre los depósitos de superficie y del subsuelo y, sobre todo, condicionan y limitan, al mismo tiempo, futuras intervenciones 
en dichos sitios. Todo ello se une al problema de la recogida de cerámicas diagnósticas, es decir, aquellas consideradas tradicionalmente como fósiles-guía, y a los avances que se han producido en el conocimiento de la secuencia arqueológica, en la definición de horizontes de cultura material y en ciertas precisiones cronológicas establecidas sobre diversos conjuntos cerámicos.

Así las cosas, tras unos primeros ensayos experimentales con transect en algunos de los asentamientos localizados en el vaso de la presa de Giribaile (Gutiérrez 2002; Fig. 1), llevamos a cabo un primer muestreo sistemático en el área arqueológica asociada al santuario heroico de El Pajarillo (Gutiérrez et al. 1998). Esa intervención permitió fijar las primeras pautas del método que comenzamos a denominar microprospección arqueológica y también el diseño de lo que en Jaén se viene conociendo como cuadrícula móvil.

\section{LA MICROPROSPECCIÓN ARQUEOLÓGICA}

\subsection{Antecedentes}

Una vez generalizado el método de prospección a grandes territorios y a unidades físicas y geomorfológicas completas, con casos ejempla- res de estudio como el valle del río Salado de los Villares (Ruiz Rodríguez et al. 1990), surgió la necesidad de análisis cada vez más detallados y pormenorizados, cambiando la escala de actuación desde el territorio al asentamiento.

Paralelamente, animados por los trabajos anglosajones que surgieron a finales de los 1950, nos decidimos a aprovechar, en el ámbito de la prospección, el alto potencial de información que aportan los materiales presentes en la superficie de los sitios arqueológicos. Un argumento importante a la hora de reivindicar una nueva formulación para este tipo de estudios procedía de la formación de una conciencia general sobre la necesidad de avanzar en el conocimiento arqueológico sin destruir el registro. De esta forma se superaba la tradicional dependencia de la prospección respecto de la excavación, a imitación de los estudios anglosajones de los nuevos arqueólogos americanos que habían proliferado especialmente en los 1960 y 1970 en el ámbito de la CRM (Cultural Resource Management). Esa tendencia había comenzado a manifestarse en una primera generación de estudios de colecciones controladas de materiales de superficie que se habían desarrollado en España desde mediados de los 1980 (Fernández y Lorrio 1986).

También resultó de un gran interés para nosotros la publicación, por aquellos años, de los pri-

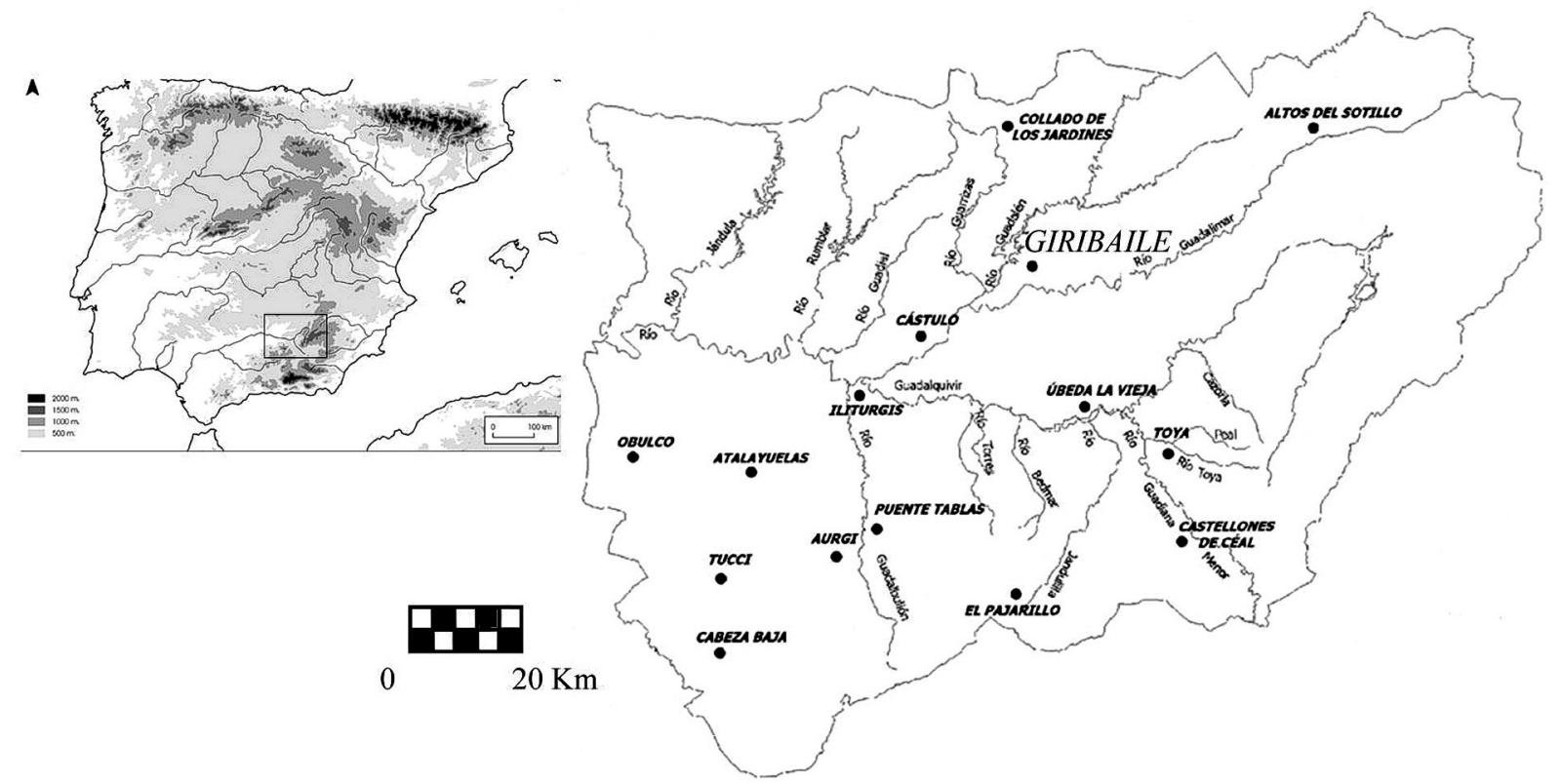

Fig. 1. Localización de Giribaile y de algunos de los sitios de ocupación ibérica y romana mencionados en el texto. 
meros informes de los proyectos de investigación sistemáticos en Andalucía por parte de equipos procedentes de universidades británicas, como el planteado en la antigua ciudad de Celti (Keay et al. 1993) y también en el hinterland de Tarraco (Carreté et al. 1995). Este tipo de análisis de superficie, vinculados a una larga tradición de estudios de carácter experimental llevados a cabo en toda la cuenca del Mediterráneo (Snodgrass y Bintliff 1991), hubiera marcado una línea de actuación con un alto potencial de información, de haberse incorporado como una práctica habitual a los trabajos de campo, reservando la excavación arqueológica a actuaciones cada vez más puntuales.

Este marco de referencia, que hemos intentado describir brevemente, nos servía de estímulo para el desarrollo de una metodología propia de trabajo. En El Pajarillo nuestra labor se centró en determinar la extensión real de los restos arqueológicos y la naturaleza del registro, profundizando en el conocimiento de aquellos factores que más influían en su representatividad y que, por tanto, debían ser tenidos en cuenta a la hora de interpretar correctamente los mapas de distribuciones que íbamos definiendo. Esta actividad también nos brindaba la oportunidad de continuar valorando la viabilidad de nuevos procedimientos analíticos. Un trabajo de estas características, llevado a cabo en el interior de un asentamiento, pone más de manifiesto la necesidad de primar ante todo la calidad de la documentación obtenida, potenciando estrategias intensivas de prospección. Entendemos como tales toda inspección y colección superficial de materiales basada en un muestreo que proporcione una localización exacta de referencia, permitiendo establecer un control espacial sobre el contexto y obtener muestras representativas (Lewarch y O'Brien 1981). En nuestro caso, la naturaleza de la población, los oppida ibéricos del alto Guadalquivir, no permitía cuantificar con los elementos de registro, mayoritariamente cerámicas, individualmente (dada la elevada cantidad de ítems), por lo cual debimos recurrir a estrategias de muestreo basadas en unidades de selección definidas espacialmente a partir de una rejilla de referencia. Esta técnica permite definir fronteras y localizar la posición de construcciones e, incluso, de áreas de actividad en sitios específicos (Fasham et al. 1980: 6).

En esta primera caracterización de un sitio arqueológico, completo, a partir de sus restos de su- perficie, decidimos recoger una muestra estratificada de cuadrículas de forma sistemática, pero no alineada, utilizando en su selección una tabla de números aleatorios. Este tipo de muestreo está recomendado especialmente para la prospección intensiva dentro de los asentamientos. La elección de una forma geométrica cuadrada para las unidades de muestreo mejora la información sobre la procedencia de los ítems recogidos y la hace más precisa, además de reducir, teóricamente, la mezcla de materiales procedentes de diferentes áreas de actividad y períodos cronológicos. La elección del tamaño de la rejilla depende de muchos factores, especialmente del análisis de la naturaleza del registro en campos arados y del detalle con el que se quiera llevar a cabo la prospección, así en algunos manuales se recomienda un módulo de entre 20 y $30 \mathrm{~m}^{2}$ (Drewett 1999: 47).

En esta ocasión actuaron como estratos artificiales, los cuadros del olivar de superficie en torno a los $100 \mathrm{~m}^{2}$. Como los olivos estaban plantados a una distancia aproximada de unos $10 \mathrm{~m}$ uno de otro, la tabla de números aleatorios empleada contemplaba los números del 00 al 99, sometiendo a cada estrato a un muestreo aleatorio simple. El muestreo con reemplazamiento se realizó de forma sistemática en todos los estratos. Trabajamos sobre un módulo base de registro de $1 \mathrm{~m}^{2}$, recogiendo una fracción muestral de un $2 \%$, que consideramos, en principio y como un valor teórico, suficientemente representativa para hacernos una idea global del conjunto de la población. Estadísticamente, es de sobra conocido que la significación del muestreo depende de su tamaño absoluto medido en unidades de muestra independientes, lo más pequeñas que sea posible, y de su reparto y distribución espacial, más que del porcentaje absoluto de la superficie muestreada. La precisión de un muestreo es una función que depende básicamente del control espacial del sitio arqueológico, medido por el número de unidades de muestra y por su tamaño, antes que de la fracción muestral. Además, la forma y el tamaño de las unidades favorecen las prospecciones uniformes, sistemáticas, de cobertura total. La superficie total en la que se repartían los restos arqueológicos en el santuario de El Pajarillo comprendía un total de 342 cuadrículas de $100 \mathrm{~m}^{2}$ cada una, el equivalente a 3,42 ha.

Una vez establecido este esquema preliminar y señalado el lugar exacto que correspondía a cada una de las unidades que debían ser mues- 
treadas, con ayuda de la cuadrícula móvil se recogieron todos los vestigios arqueológicos que fuimos capaces de observar en superficie, siguiendo un criterio fijado de antemano que consistía en incluir todos los materiales que formaran parte del registro móvil. La interpretación de los resultados obtenidos nos permitió establecer una nueva perspectiva sobre el monumento excavado.

\subsection{Muestreos en prospección arqueológica}

Actualmente, los trabajos de prospección arqueológica tienen un papel relevante en la interpretación de los paisajes culturales (Orejas 1996). Estos análisis globales han dado una nueva dimensión a los objetivos de investigación, superando enfoques tradicionales restrictivos que sólo permitían obtener lecturas parciales sobre los territorios o los asentamientos en estudio. Por otra parte, el desarrollo de los estudios de la Arqueología del Paisaje se ha visto favorecido por la implantación, cada vez más generalizada, de los Sistemas de Información Geográfica (SIG) (García Sanjuán 2005; Grau 2006), un nuevo escenario de reflexión sobre la capacidad potencial de información de los datos que plantea retos interesantes, y por una creciente mejora en el registro espacial gracias a los sistemas de localización GPS.

Para completar estos estudios sería de un gran interés contar con muestreos arqueológicos rigurosos y generalizados dentro y fuera de los asentamientos. A menudo la aplicación de los sistemas de georreferenciación GPS no supera la barrera del análisis de dispersiones de artefactos de baja intensidad (Schiffer et al. 1978: 2) ni aborda el registro de grandes colecciones de materiales, especialmente cuando se salta de la escala del territorio a la definición de una ocupación estable y compleja. Es este, precisamente, nuestro interés principal a la hora de desarrollar un protocolo de trabajo en el ámbito de lo que hemos convenido en llamar microprospección arqueológica.

La microprospección pretende proporcionar un modo de análisis común y generalizable dentro de los asentamientos que prime la calidad de la documentación del registro de superficie, redefina el concepto de sitio arqueológico sobre la base del estudio estadístico de las colecciones de materiales y planifique estrategias de trabajo intensivas, profundizando en los problemas planteados por los muestreos arqueológicos. Esta nue- va definición del asentamiento debe basarse en estudios topográficos precisos y en la incorporación de los últimos avances en sistemas de detección bajo la superficie del terreno (fotointerpretación, teledetección, prospección geofísica, prospección sub-superficial en zonas de baja visibilidad, etc.), permitiendo una amplia variedad de opciones que pueden ser empleadas según las necesidades, los objetivos de nuestros proyectos y la disponibilidad de medios. Pese a que este crecimiento técnico nos sitúa en una etapa del desarrollo de la prospección muy avanzada respecto a tiempos no demasiado lejanos, en ningún caso debe renunciarse a uno de los principios generales de la prospección: su intensidad, en términos de control de la distancia de separación entre los prospectores o de la cuantificación del número de personas-día empleadas por cada unidad de muestra (Cherry 1983: 390).

Nuestros trabajos de microprospección deben entenderse en esta línea de recuperación de planteamientos, hoy "clásicos", sobre la elaboración de una taxonomía de sitios a partir de la comparación de los registros de superficie que permita caracterizarlos funcionalmente (Binford 1964) o de definición, más reciente, de los sitios arqueológicos con relación a un estudio de la distribución de las densidades de artefactos a escala regional (Plog et al. 1978). Aunque en Giribaile se pretende la definición de la cultura material dentro de una ciudad, de cierta entidad en el contexto de la Cultura Ibérica, sería aconsejable que este tipo de práctica metodológica se empleara también en el ámbito de lo que se ha venido en denominar off-site survey. Se abordaría así el espinoso problema de qué entendemos en cada caso por "sitio" ya que, frecuentemente, la naturaleza de los procesos de formación del registro arqueológico sugiere una distribución continua de materiales sobre el terreno (Foley 1981: 157). Esta dinámica de prospección en multiestadíos que combina actuaciones a muy diferentes escalas debería contemplar una cadena operativa, al menos, en tres etapas: el análisis de las variaciones en las densidades de las concentraciones de materiales, el estudio de la estructura potencial de los datos y, finalmente, la interpretación de cada una de las particulares extensiones de materiales (Bintliff 2000: 200).

La práctica generalizada de registros de visibilidad y de densidades de artefactos en superficie debería convertirse así, en una rutina habitual en 
el diseño de las prospecciones en el ámbito mediterráneo (Gallant 1986: 418), a pesar de que no resulta sencillo transferir las metodologías desarrolladas para los regímenes agrícolas y las condiciones climáticas que prevalecen en las regiones templadas del norte de Europa o semiáridas del Sureste de los Estados Unidos (Gaffney et al. 1991: 63 y 76). Para conseguir este objetivo debería aplicarse una metodología básica en dos niveles de resolución, dentro y fuera del asentamiento, utilizando rejillas regulares (como en el caso de nuestras propuestas de microprospección) o transects adaptados a la disposición de las propiedades y campos de cultivo actuales (Gillings y Sbonias 1999). Pautas como las marcadas por el proyecto pionero de la expedición Cambridge/Bradford en Beocia (Bintliff y Snodgrass 1985: 127) afrontan las circunstancias particulares que presentan estos paisajes, con una historia, a menudo, bien documentada, una alta densidad de materiales en superficie y una presión creciente, derivada de la intensificación de los cultivos.

La práctica de las prospecciones sistemáticas superficiales en el ámbito mediterráneo se ha considerado problemática, de forma explícita, con la aparente paradoja de que, a pesar de aplicar procedimientos técnicos sofisticados y un control sobre los procesos geológicos que afectan a la superficie, los problemas no desaparecen (Wandsnider 2004: 70-72). Esta clase de trabajo debería proporcionar información sistemática y cuantificable para resolver problemas a escala local y regional. Las comparaciones significativas entre asentamientos a partir de la detección de patrones recurrentes de materiales puede permitir en el futuro elaborar análisis de poblamiento precisos, estudios demográficos (Bintliff y Sbonias 1999) y generar modelos predictivos, etc., sin olvidar que la relación que puede establecerse entre las evidencias de superficie y enterradas es, indudablemente, compleja y varía de un sitio a otro (Renfrew y Bahn 1991). Como ha apuntado N. Terrenato (2004: 43-45), la integración de diferentes conjuntos de datos corresponde a un ejercicio global de interpretación basado en el contexto local más que en una observación objetiva. Sin embargo, las comparaciones entre sitios y medio ambiente son fiables y muy deseables, ya que casi siempre la única integración posible se producirá a nivel cualitativo, dado el alto grado de variabilidad medioambiental en las diversas regiones del Mediterráneo.
Los trabajos específicos de caracterización de la cultura material de superficie llevados a cabo dentro de los asentamientos son todavía minoritarios (Walker 1985; Mattingly y Coccia 1995; Vermeulen 2005: 987-988), si los comparamos con el número de actuaciones que, mediante las dispersiones generales de materiales a lo largo y ancho del territorio, investigan los cambios en el uso de la tierra durante amplios períodos y las modificaciones producidas en la ocupación rural. La amplia gama de estrategias de prospección desarrolladas siempre han atendido a los problemas derivados del cultivo del terreno y a la consideración de los procesos geomorfológicos (Mills 1985). La aplicación de estas técnicas en las últimas décadas ha venido de la mano de nuevos enfoques de investigación. El campo tradicional de la arqueología clásica, centrado en el análisis de los orígenes, el desarrollo, la función y el papel jugado por las ciudades mediterráneas, se ha ampliado al conocimiento de las prácticas agrícolas y de la densidad del poblamiento rural y los cambios económicos en los territorios ciudadanos (Keay 1991: 77).

En las regiones templadas, como Gran Bretaña, las prospecciones son, habitualmente, de menor tamaño y más intensivas y los registros de materiales de superficie menos abundantes (Barker 1995), que las que suelen suceder en el ámbito mediterráneo. Aquí, las limitaciones de tiempo y recursos afectan, incluso, los proyectos de investigación de larga duración que, a menudo, pese a su carácter sistemático, no llegan a abordar ni siquiera un $10 \%$ del análisis global de todo el territorio. Ello ha llevado a promover propuestas pragmáticas que intentan rentabilizar al máximo el balance de los esfuerzos de prospección entre los muestreos realizados en un sitio específico y a escala más amplia, considerando todo el territorio. En esta línea debe entenderse la propuesta de J.L. Bintliff (1992: 98-100) de afrontar el trabajo en los sitios potenciales que van siendo descubiertos como si se tratara de mini-paisajes, reduciendo a la mitad la anchura de los transects y, consiguientemente, el tiempo excesivo requerido para la localización exacta de las unidades de muestreo. Nuestra propuesta de microprospección en Giribaile debe entenderse como una actuación complementaria. En general, la mayor parte de los trabajos apuntan a la necesidad del control geomorfológico de los datos (Brown 1999) y del necesario equilibrio entre las pros- 
pecciones extensivas, a gran escala, y las intensivas, centradas en la investigación de objetivos concretos, en el marco de una estrategia de muestreos en fases sucesivas y complementarias, aplicando un diseño en estadíos múltiples (Wilkinson 2004b).

Finalmente, como recuerda M. Millet (2000b: 220), debe avanzarse en el tratamiento estadístico de variables como el índice estimado de equivalencia que representa un fragmento de cerámica sobre la pieza completa, frente a las que venimos utilizando habitualmente del número total de fragmentos o su peso total. Estas dependen de factores tales como el grosor de las paredes del recipiente, su forma o su tamaño, favoreciendo la variable del peso a los recipientes de paredes más gruesas y a los de paredes más delgadas la variable que tiene en cuenta el número total de fragmentos.

Esta vía experimental, que en la arqueología española no ha llegado a definir una línea clara de actuación a pesar de algunos ensayos pioneros de los 1980, empieza a generalizarse en la práctica arqueológica de proyectos de investigación con intereses muy diferentes que incluyen la prospección intensiva, en diversos grados (Hurtado 2000; Barton et al. 2004; Burillo 2006).

\subsection{La cuadrícula móvil}

La cuadrícula móvil (Lám. I) es una estructura desmontable de aluminio, compuesta por 16 largueros de $1 \mathrm{~m}$ de longitud y cuatro esquinas que forman escuadras con $0,5 \mathrm{~m}$ de largo en cada lado. Con estas cuatro esquinas y un número variable de largueros se puede montar un cuadro

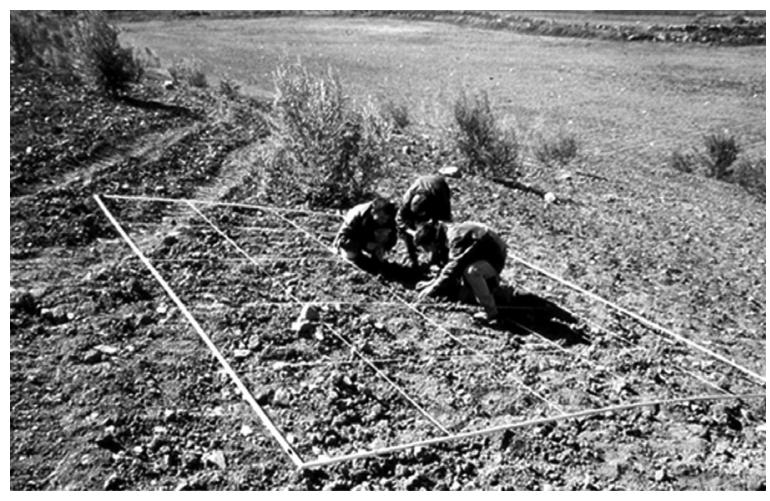

Lám. I. Santuario heroico de El Pajarillo (Huelma, Jaén). Utilización de la cuadrícula móvil. con un tamaño mínimo de $2 \times 2 \mathrm{~m}$ y máximo de $5 \times 5 \mathrm{~m}$. Este ingenio, de tamaño variable, puede subdividirse en unidades de $1 \mathrm{~m}^{2}$, ya que los largueros presentan una perforación en el centro para facilitar el enganche de gomas elásticas a la estructura.

El precedente de la cuadrícula móvil es un prototipo de madera utilizado en el proyecto $\mathrm{Ke}$ ban Reservoir. Allí se empleó como modo para centrar la atención de los prospectores en un espacio concreto y bien delimitado dentro de un transect (Whallon 1983: 75, 76 y 79). En nuestro caso fue diseñada para reducir los costes de localización de las unidades que debían ser muestreadas y conseguir el difícil equilibrio entre el tamaño, lo más reducido posible, de las unidades de muestra y la precisión de la información espacial, un problema considerado crítico en esta clase de prospección.

La cuadrícula móvil ha mostrado su versatilidad y eficacia en los numerosos trabajos que hemos llevado a cabo en diferentes terrenos. Se trata de una estructura rígida, pero ligera, transportable por sólo dos personas. Su tamaño fue pensado para abordar la situación más frecuente en las prospecciones arqueológicas en la provincia de Jaén, donde el uso actual del suelo confiere una gran importancia al cultivo del olivar. La cuadrícula móvil se adapta a estas formaciones en hilera, en las que los olivos se plantan a distancias regulares que, tradicionalmente, oscilan entre 8 y $12 \mathrm{~m}$. Como convención general, tomamos como unidad mínima de trabajo el espacio libre entre cuatro olivos, enfrentados dos a dos, asumiendo que cuatro olivos situados en dos hileras paralelas ocupan las esquinas de una supuesta cuadrícula teórica. Al repensar la geometría del olivar en términos de muestreo arqueológico cada calle se convierte en un transect y, a su vez, estos se subdividen en cuadrículas (Lám. II).

Sólo faltaba adoptar un módulo de referencia para decidir el tamaño de la cuadrícula móvil. En el olivar tradicional se plantan los olivos, aproximadamente, cada $10 \mathrm{~m}$, por lo que forman cuadros de $10 \times 10$, una superficie cercana a $100 \mathrm{~m}^{2}$. La cuadrícula móvil podría abarcar, en su versión máxima de $5 \times 5 \mathrm{~m}, 25 \mathrm{~m}^{2}$, es decir, un divisor de 100. La ventaja es que, como cada esquina de la cuadrícula viene definida por un olivo, a partir del centro teórico de la cuadrícula este espacio se divide en cuatro unidades de $25 \mathrm{~m}^{2}$. Es decir, si apoyamos la cuadrícula móvil en la pata de cada 


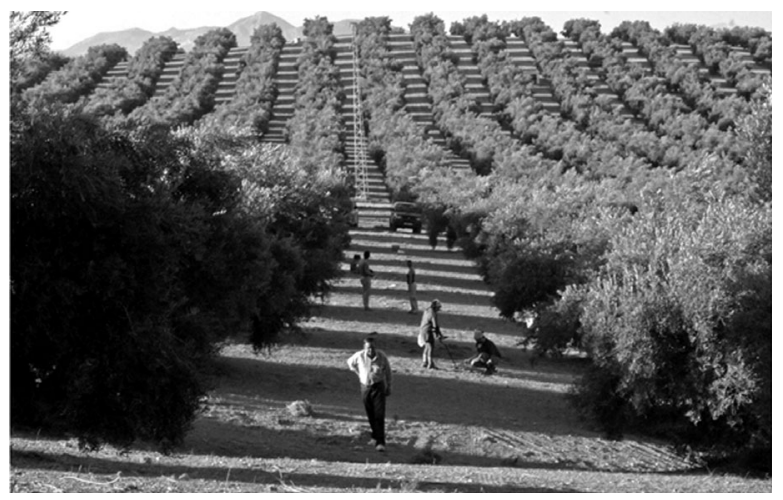

Lám. II. Cerro de las Albahacas (Santo Tomé, Jaén). Proyecto Baecula.

uno de los olivos-esquina de la cuadrícula es posible abordar todo el espacio muestreable.

Somos conscientes de que se introducen errores. En primer lugar el propio espacio que ocupan los olivos varía en función de su edad y tamaño y del hecho de que tampoco los olivos están situados exactamente cada $10 \mathrm{~m}$, si bien cualquiera que conozca la disposición de los olivares de Jaén se asombra de las alineaciones tan perfectas y regulares que en muchas ocasiones se pierden en el horizonte. Como ya hemos comentado estamos tratando de adaptarnos al olivar-tipo que predomina actualmente en el paisaje de Jaén, mayoritariamente con olivos de una o tres patas, en ocasiones centenario. Sin embargo, en el trabajo de campo podemos encontrar olivares de regadío y cultivo intensivo que reducen las distancias tradicionales. La forma del cuadro también se puede ver afectada por la topografía del terreno. Cuando se aprovechan las laderas de una montaña o las hileras de olivos giran y se adaptan a una curva de nivel, predominan las formaciones irregulares y en trebolillo que pueden llegar a romper completamente la disposición tradicional de los olivos enfrentados en hileras. Incluso, en esos casos, mantenemos la geometría que marca el olivar como la base de referencia de nuestro muestreo, aunque, a veces se trate de cuadrículas muy irregulares o de espacios que ni siquiera podemos denominar cuadrículas, ya que adoptan formas de rombos, triángulos, trapecios, etc. Esta manera de proceder permite planificar adecuadamente las unidades de muestreo en los trabajos preparatorios de la prospección en el laboratorio, donde las fotografías aéreas en color de las zonas de estudio con una resolución espacial de $1 \mathrm{~m}$ nos permiten identificar el número total y la disposición de las unidades que deben ser muestreadas, ya que los olivos son perfectamente reconocibles.

\section{EL CASO DE GIRIBAILE}

En 2004 llevamos a cabo una actividad arqueológica de prospección en los terrenos pertenecientes al oppidum de Giribaile. El proyecto era una propuesta concreta para la definición y caracterización arqueológica rigurosa de la cultura material presente sobre la superficie de la meseta. Se intentaba una lectura diacrónica del proceso histórico de dicho sitio arqueológico, que confirmara o no las hipótesis planteadas a partir de las antiguas campañas de excavación y favoreciera, al mismo tiempo, la investigación y la puesta en valor del yacimiento con vistas a la inauguración del CIAG (Centro de Interpretación Arqueológica de Giribaile). La actuación arqueológica incluía un estudio topográfico y trabajos de prospección tanto en la meseta de Giribaile, como en su entorno más inmediato.

\subsection{Topografía de Giribaile. Definición del espacio de trabajo}

La meseta de Giribaile presenta unas condiciones magníficas para la realización de esta clase de trabajo. Se trata de un espacio completamente cerrado y en altura, protegido por grandes cortados de roca, auténticos farallones en algunos puntos, que lo convierten en un recinto con unos límites precisos, un gran contenedor de restos arqueológicos, metafóricamente hablando, del que es posible que salgan materiales, debido a causas de origen diverso, pero no que estos se contaminen con nuevas aportaciones procedentes de lugares cercanos. De hecho, al recorrer los aleros de roca del farallón y el pie de los acantilados de Giribaile resulta relativamente frecuente encontrar fragmentos de cerámica de tamaños muy diversos, a veces poco rodados, que, aparentemente, proceden de la meseta y que, por tanto, deben haber caído en diferentes momentos desde que esta fue abandonada como lugar de hábitat, definitivamente, a partir de la Edad Media.

Además de por sus características topográficas, Giribaile resulta un caso excepcional a la hora de poder precisar el área arqueológica: 14,56 ha. Una fortificación de tipo barrera cierra completamente 
la parte de la meseta correspondiente a la antigua ciudad ibérica y permite obviar uno de los grandes problemas a los que, habitualmente, debe enfrentarse la prospección arqueológica a la hora de estimar la superficie de un asentamiento: la valoración y consideración de la extensión de restos de superficie, en nuestro caso mayoritariamente cerámicas. A priori, sabemos que los restos presentan distintos grados de desplazamiento desde su contexto de origen, debiendo diferenciarse un núcleo de un halo o periferia, especialmente en terrenos cultivados (Alcock et al. 1994: 141-142) y atendiendo a factores como el clima o la vegetación, que pueden ser utilizados como controles geológicos y pedológicos para determinar el grado de erosión que afecta a las colecciones de superficie (Bintliff y Snodgrass 1988: 511).

En nuestro esquema de trabajo resulta imprescindible una topografía de detalle, previa a los muestreos arqueológicos. Esto nos facilita un detenido análisis y documentación de las evidencias de superficie (cerámicas, cimientos de construcciones, líneas de rotura del terreno, etc.). El estudio topográfico, que incluye la meseta de Giribaile y su entorno más inmediato, cubre un área de 63 ha. La topografía partió de una ortoimagen a color a escala 1: 5.000 que, con el apoyo de los posteriores trabajos de campo, logró errores de precisión espacial inferiores a los $20 \mathrm{~cm}$. El estudio topográfico nos ha permitido delimitar con exactitud la forma del oppidum. Se localiza en el extremo de una meseta alargada y se extiende a lo largo de un eje de algo más de $900 \mathrm{~m}$ con una orientación predominante suroeste-noreste, ocupando dos grandes espacios denominados, respectivamente, Plataforma Principal y Plataforma Norte (Fig. 2).

La Plataforma Principal toma como origen el tramo de la fortificación ibérica conocido como dispositivo de tipo barrera. Este, con una longitud de $246 \mathrm{~m}$ y más de $10 \mathrm{~m}$ de altura conservados en algunos puntos, interrumpe el suave ascenso a la meseta, impidiendo la libertad de acceso al interior de la ciudad a través de su flanco más vulnerable. A partir de aquí se abre una superficie amplia de terreno, en torno a las 9 ha, de tendencia rectangular, con una longitud de $520 \mathrm{~m}$ que mantiene una línea recta, constante, en su flanco noroeste y un arco de círculo en su límite sureste, cerrando el espacio progresivamente hasta morir en el punto natural más elevado, un estrangulamiento que separa la Plataforma Principal de la Plataforma Norte. En este lugar aflora en superficie la roca de base geo- lógica y parecen confluir las principales líneas de tránsito y circulación que comunican el oppidum con su entorno más inmediato. Al menos, así se debe interpretar la pérdida de altura del escarpe y la existencia de un camino antiguo reconocible, al menos, desde las cuevas de Giribaile.

Por su parte, la Plataforma Norte se extiende desde el estrechamiento de la meseta hasta el espolón donde se localiza el castillo. Se trata de un terreno de aproximadamente 4,4 ha, menos de la mitad de la superficie de la Plataforma Principal, que, topográficamente, se configura como un espacio de tendencia triangular que se va cerrando en dirección noreste, hasta alcanzar el castillo medieval. Este lugar constituye un punto privilegiado dentro de la meseta por los acantilados que lo rodean y que le sirven de defensas naturales. Además hay que tener en cuenta que la vaguada que lo antecede, en la que aflora la roca, le sirve para establecer una distancia física respecto al resto de la meseta, proporcionándole una posición de control y de dominio visual sobre el entorno circundante. En general, al igual que sucedía con la Plataforma Principal, la Plataforma Norte también está levantada sobre fuertes acantilados, especialmente en su ángulo noroeste, un lugar óptimo para el estudio de la secuencia geológica de la meseta de Giribaile.

Con estas condiciones topográficas, el espacio que conforma la meseta se muestra, en general, como una extensión amplia y abierta, aparentemente, sin más limitaciones que las que corresponden al castillo medieval y al dispositivo de la fortificación ibérica de tipo barrera. Sin embargo, una aproximación de mayor detalle nos permite definir ciertos obstáculos para el desarrollo de nuestro trabajo de campo, comenzando por el que hemos venido denominando como poblado intramuros.

El poblado intramuros se localiza inmediatamente después de traspasar la fortificación de tipo barrera. Se encuentra basculado hacia el reborde septentrional y limita al noroeste con un afloramiento de roca perteneciente a la base geológica del terreno, mientras que hacia el sureste no alcanza el reborde de la meseta. Se trata de una importante acumulación de piedra repartida por unas 2,5 ha, en las que una observación detenida permite reconocer, junto a pequeños montones de piedra y grandes bloques in situ, alineaciones de muros correspondientes a los zócalos de varias viviendas que marcan la tendencia predominante en la orientación de las casas en el urba- 

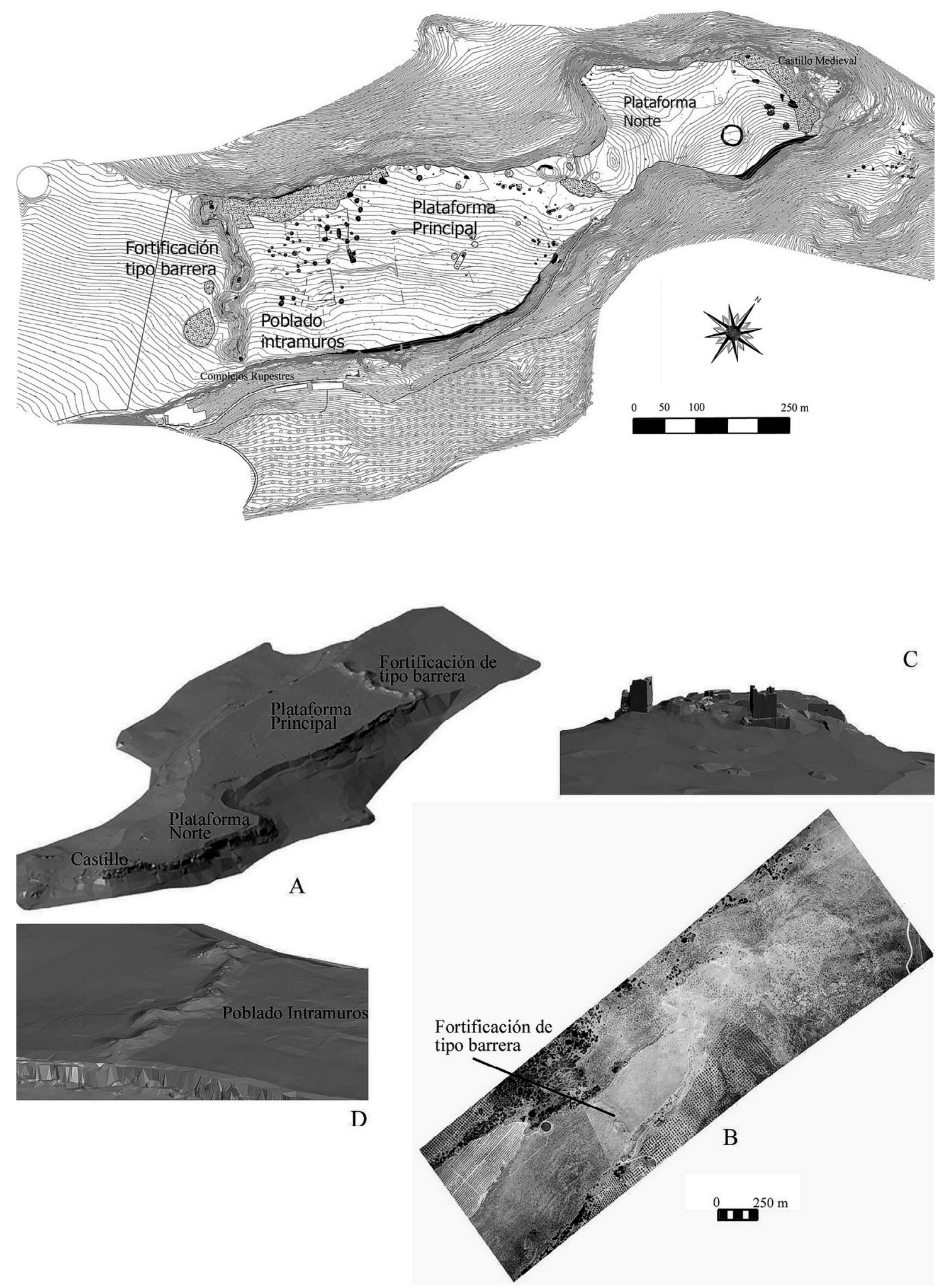

Fig. 2. Topografía de Giribaile (Jaén). A. Restitución informática de la topografía como un volumen sólido. B. Detalle de la fortificación de tipo barrera. C. Castillo medieval. D. Ortoimagen de Giribaile.

T. P., 67, N. ${ }^{\circ}$ 1, enero-junio 2010, pp. 7-35, ISSN: 0082-5638 doi: $10.3989 /$ tp.2010.10029 
nismo presente en la Plataforma Principal para época ibérica. Como límite sureste del poblado intramuros actúa un talud con forma de $\mathrm{U}$, con un desnivel de 1,5 m.

Los trabajos de topografía muestran una depresión del terreno en la Plataforma Principal, al noroeste del afloramiento de roca que le sirve de separación respecto a la Plataforma Norte. En la Plataforma Norte es posible reconocer un gran cercado de piedra en las inmediaciones del castillo medieval. Este último se define como un espacio fortificado próximo a 1 ha, en el que resultan complicados los trabajos de microespacio a causa del nivel de colmatación que se observa en superficie y de las limitaciones de espacio disponible, por las construcciones interiores dentro del recinto, entre ellas una cisterna.

\subsection{Factores que influyen en el registro de superficie}

Son muchos los procesos de formación, culturales y no culturales, que influyen en la representatividad de los contextos arqueológicos (Reid et al. 1975: 212). De ahí que los factores a considerar sean muy variados y de muy diversa índole y que todos ellos deban tenerse en cuenta a la hora de interpretar los resultados obtenidos en una intervención de prospección arqueológica superficial. Una aproximación objetiva requiere la puesta en práctica de técnicas de prospección y muestreo correctas y la consideración de las variables que rigen los datos observables, sin olvidar la valoración de los factores postdeposicionales que tienen que ver con su distribución, conservación y visibilidad (Foley 1981: 166).

Resulta necesario definir, por tanto, la coherencia del conjunto y de nuestro método de trabajo antes de intentar interpretarlo. Estos factores tienen que ver con las propias condiciones naturales del terreno, en nuestro caso marcado por un patrón de erosión y vegetación característico de un medio semiárido, y con el uso que de él se ha hecho a lo largo del tiempo. Es preciso estudiar los factores de alteración naturales y también asociados a la propia acción del ser humano, que influyen en la disposición del registro, en la manera de distribuirse las colecciones de ítems en superficie. Éstas han sido estudiadas en un momento concreto de la historia, en una determinada coyuntura cero, en nuestro caso el período que media entre el 22 de noviembre de 2004 y el 5 de abril de 2005.
Los conjuntos de artefactos presentes sobre los terrenos actuales de la meseta de Giribaile se han agrupado en diversas categorías. Éstas permiten clarificar la complejidad de los procesos postdeposicionales que intervienen en la construcción de los registros superficiales actuales.

\subsubsection{El medio físico}

Entre los factores naturales que afectan a los depósitos arqueológicos pueden citarse las propias características geológicas y geomorfológicas del terreno, el tipo de suelo, las pendientes, la erosión, la cubierta vegetal, la actividad de organismos, etc.

A menudo no se dispone de mucha información al respecto, pero Giribaile cuenta con trabajos específicos de geología, por sus características peculiares. La meseta, fracturada por una falla, está formada por un antiguo relleno sedimentario marino de la cuenca del Guadalquivir, depositado en un sistema deltaico y de plataforma (García-García et al. 2003), sobreelevado sobre su entorno y posteriormente erosionado, de ahí que sea frecuente encontrar abundantes fósiles marinos al recorrer la meseta y, por el contrario, no se observan las fértiles tierras rojas, triásicas, que se extienden por todo el valle.

La falta de suelo, con afloramientos de roca en superficie en la mayor parte de la meseta, reconocibles en varios puntos de la zona arqueológica, junto con los ricos acuíferos y manantiales, que se concentran a la altura de las cuevas excavadas en la base del farallón de roca sobre el que se alza la meseta, facilitaron la construcción de una ciudad y la convirtieron en un terreno apto para el desarrollo de una ganadería extensiva y de otros aprovechamientos agropecuarios, de gran importancia en la economía del mundo antiguo.

Las características generales del medio físico han sido descritas, en parte, al tratar la definición del espacio de trabajo, si bien la topografía permite determinar con mayor precisión el índice de las pendientes que rodean la meseta en cada punto y las principales líneas de erosión que afectan a la circulación de los materiales. Algunos indicadores arqueológicos como la pérdida de parte de la fortificación perimetral del oppidum pueden resultar de gran importancia para comprender la entidad de este proceso.

La Plataforma Principal, protegida por grandes farallones, presenta un declive natural en di- 
rección suroeste, de modo que las principales líneas de erosión tienden a mover los materiales hacia el precipicio que mira hacia el valle del río Guadalimar, como demuestra también la pérdida, casi completa, de la muralla en el reborde de la plataforma de este tramo, a pesar de la descripción de Manuel de Góngora (1860), cuando al respecto comenta que "... En el perfil de la peña apenas se interrumpen los restos de muro". Actualmente, sólo se reconocen las ruinas de murallas al descender por los aleros del acantilado. Por el contrario, en el flanco noroeste, aunque la fortificación no conserva su alzado, es posible seguir en planta una sucesión de alineaciones de muros con una anchura entre 1 y $2 \mathrm{~m}$, que se unen en ángulo recto, adaptándose de este modo a la forma del reborde de la propia meseta. Estos muros, de los que sólo se conservan sus cimientos, continúan a la fortificación perteneciente al dispositivo de tipo barrera.

El levantamiento topográfico muestra en la parte central de la Plataforma Norte un espacio fuertemente colmatado y de acceso dificultoso, por el crecimiento espontáneo de arbustos, en ocasiones de más de $1 \mathrm{~m}$ de altura, a partir del cual se organizan las principales líneas de erosión que, en este caso, siguen una orientación predominante hacia la vertiente sureste.

\subsubsection{La acción del ser humano}

Pueden citarse como principales factores de alteración de carácter antrópico los diferentes usos del suelo, las expoliaciones, la redeposición de sedimentos en tiempos recientes, etc.

Para poder interpretar las distribuciones de materiales correctamente, en el marco teórico de la denominada ploughsoil archaeology o, más recientemente, artefact scatters, es necesario conocer la naturaleza y la intensidad del uso de la tierra (Stoddart y Whitehead 1991: 141). Las condiciones geológicas de la meseta de Giribaile no son favorables para la práctica de la agricultura. Tan sólo ha sido posible llevar a cabo una agricultura de subsistencia en la parte de la meseta correspondiente a los terrenos del antiguo oppidum. Actúan como suelo los propios depósitos arqueológicos, formados por la tierra de los tapiales y adobes de las paredes de las casas, una vez que estas fueron destruidas y el paso del tiempo permitió la formación de un nivel de tierra compacto, apro- vechado siglos más tarde para cultivar el antiguo solar que ocupó la ciudad ibérica. En la antigüedad la situación debió ser muy diferente, ya que como demuestran las prospecciones arqueológicas llevadas a cabo a principios de los 1990, los asentamientos agrícolas para la etapa ibérica se localizaban en los valles circundantes, ocupando las terrazas más próximas a los cursos de agua principales. Así, cerca de un centenar de pequeñas factorías agrarias y almacenes, se distribuyeron de un modo capilar, ocupando los márgenes de los ríos Guadalimar y Guadalén (Gutiérrez 1998).

Actualmente, la zona arqueológica de Giribaile es un erial asociado a los cortijos cercanos, ubicados en la base del farallón de roca, donde se localizan las cuevas, si bien sabemos que hacia 1860 existían una cortijada y una huerta vecina (Góngora 1860) y hasta un momento relativamente cercano pudo ser cultivado. De todos modos, la historia agraria reciente de Giribaile es muy limitada y debería relacionarse con una agricultura tradicional, no mecanizada, por lo cual resultaría fácil determinar en futuras campañas de excavación el nivel superficial, de tierra removida, correspondiente al pie de arado. Estas condiciones limitan los efectos negativos que se relatan habitualmente en la literatura arqueológica relativa a la recogida de colecciones de superficie en zonas aradas, sintetizadas por Haselgrove (1985: 15), sobre todo por lo que respecta al desplazamiento lateral (tanto longitudinal como transversal) y vertical de los artefactos, los cambios en las clases de frecuencias entre las colecciones superficiales y los depósitos que aún permanecen enterrados, las alteraciones relativas al contenido y forma de los conjuntos distribuidos en la superficie del terreno y los cambios en la condición y preservación de los artefactos (Lewarch y O'Brien 1981: 308). Mayor importancia ha tenido en los últimos años la práctica tradicional de la ganadería en la meseta de Giribaile, utilizada como pasto para rebaños de ovejas.

Las expoliaciones han sido registradas en la topografía y se trata, en general, de una actividad limitada a la apertura de pequeños hoyos asociados al uso de detectores de metales. Esta situación contrasta con el estado de las necrópolis al pie de la meseta, en las cuales hubo trabajos clandestinos durante décadas.

La escasa importancia de la puesta en explotación de la meseta de Giribaile, unida a la baja presión por parte de expoliadores y arqueólogos, ya 
que estos últimos se habían limitado a recoger materiales de superficie puntualmente, la hacía un lugar perfecto para abordar la puesta a punto de la metodología de prospección para el registro de conjunto de colecciones de materiales de superficie en el ámbito de la microprospección arqueológica.

La primera noticia de la recogida previa de colecciones de superficie procede de Manuel de Góngora, que en 1860 recorrió estos parajes describiendo de modo cuidadoso el sitio y fotografiando algunos materiales. Más tarde, serían coleccionadas algunas piezas, consideradas especialmente interesantes, por el equipo que excavó en la meseta de Giribaile durante las campañas de 1968 y 1969 , sobre todo aquellas que se encontraban casualmente en el desplazamiento a los "pozos de prospección" durante las jornadas de trabajo. Finalmente, en 1986 se limpiaron algunos de los antiguos cortes excavados, actividad que llevó asociada una prospección centrada en los terrenos del entorno de la meseta.
Estas actividades unidas a la recogida puntual de materiales por algunos arqueólogos que, a lo largo de este tiempo, recorrieron la meseta en solitario, no habían significado una actuación sistemática de recolección de cerámicas de superficie. En nuestra opinión, no han causado un serio perjuicio a la representatividad de las colecciones de superficie, dada su entidad y envergadura en Giribaile. Sí debe tenerse en cuenta que el tamaño de los objetos decrece a medida que se realizan nuevas recolecciones. Estas pueden haber afectado sobre todo a los grupos de materiales formados por piezas que, por su forma y tamaño, no resulta fácil fragmentar como un pondus o las fusayolas, al tratarse, especialmente las primeras, de piezas macizas de grosor considerable. Así, pues, el transect que llevamos a cabo en 1993, puede ser considerado la primera recogida controlada, ordenada y sistemática registrada en el área arqueológica de Giribaile. En la Lám. III la distribución del número de piezas $/ \mathrm{m}^{2}$ refleja bien las condiciones de registro y la propia topografía de

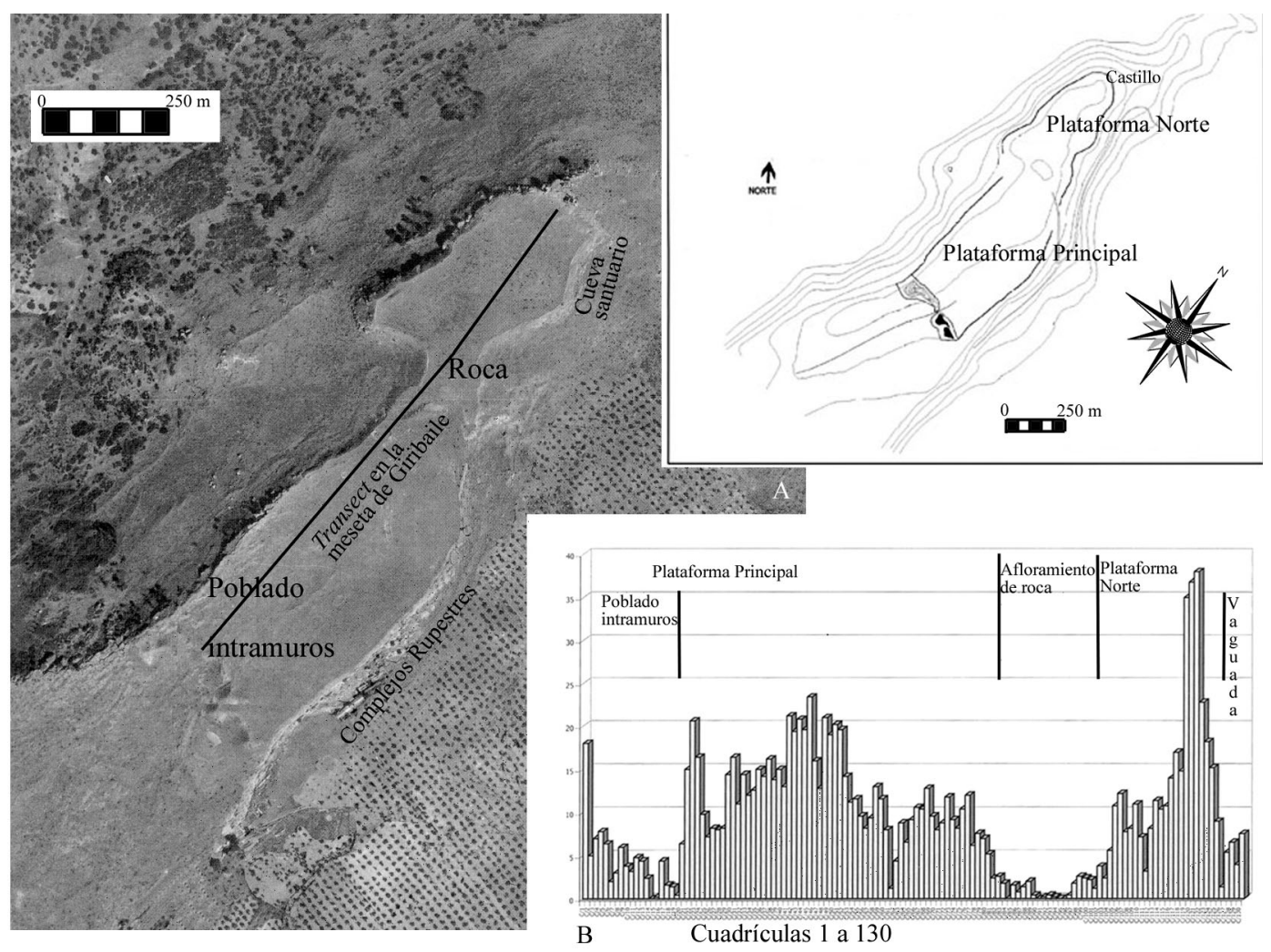

Lám. III. Transect de Giribaile (Vilches, Jaén). A. Dirección del transect. B. Variabilidad en el número de piezas $/ \mathrm{m}^{2}$ recogidas sobre la superficie del terreno. 
la meseta de Giribaile, de modo que la variabilidad de densidades del transect responde a su paso a través del poblado intramuros, la Plataforma Principal, el afloramiento de roca y la Plataforma Norte, hasta alcanzar el castillo.

\subsubsection{Complejidad de la secuencia crono-cultural}

La densidad de las ocupaciones, su número y profundidad temporal, la complejidad interna del sitio o sus diferentes funciones diacrónicas en el territorio influyen de una forma directa en la lectura de los resultados obtenidos. La variabilidad en la entidad y la densidad de la ocupación en Giribaile, alternando con períodos de abandono, más o menos prolongados, convertían este asentamiento en un lugar idóneo para experimentar nuevos procedimientos técnicos y poner a punto el método de microprospección. Resultaba relativamente sencillo establecer diferencias en los conjuntos de materiales que se asociaban a los diversos horizontes arqueológicos: cerámicas toscas, fabricadas a mano pertenecientes a comunidades de la Prehistoria Reciente; cerámicas finas a torno de época ibérica de pastas compactas, duras y sonido metálico, acabadas, en muchas ocasiones, con engobes y, finalmente fragmentos de época altomedieval pertenecientes a recipientes de gran formato, fabricados con el torno lento, con desgrasantes visibles de tamaño elevado, habitualmente con decoraciones plásticas en forma de cordones. Todos estos factores permitían unir en un mismo proyecto objetivos de investigación sobre la secuencia y metodológicos, centrados en el desarrollo de modos rigurosos de colección de materiales de superficie.

El primer asentamiento en la meseta de Giribaile se relaciona con un primitivo poblado de cabañas de la Edad del Bronce que, tal vez, alcanzara el período orientalizante. Más tarde, a principios del siglo IV a.C., sobre este antiguo solar se construyó el oppidum de Giribaile, una gran ciudad ibérica de la Oretania que formaba parte del pago de Cástulo. Finalmente, en época medieval se erigió un castillo sobre el espolón noreste, con una primera fase de construcción, posiblemente califal, y una segunda almohade. Estas ocupaciones, separadas por largos períodos de abandono, facilitan nuestro trabajo de reconocimiento de materiales y, en general, presentan límites espa- ciales precisos. El castillo ocupa un espolón de roca diferenciado y separado por una vaguada del resto de la meseta. El oppidum, que unifica toda la zona arqueológica y constituye el espacio principal de actuación de la microprospección, presenta, igualmente, claros límites topográficos.

Una vez abandonados los valores estratégicos que determinaron la ocupación de la meseta, los criterios que determinan la localización de los cortijos instalados en la base de las cuevas son la protección que proporciona el farallón de roca, la proximidad a los nacimientos de agua que se concentran en la base de la meseta, los olivares cercanos, etc. Estos cortijos, la mayor parte de ellos hoy en ruinas y abandonados, utilizados por cazadores o como viviendas de fin de semana, son la versión más actual de la ocupación de las cuevas, descrita por J. Maluquer (1976: 20): "En el risco que sostiene la meseta del poblado, existen numerosas cuevas artificiales ocupadas como viviendas temporalmente por los aceituneros en época de recolección", relegando a un segundo plano a la meseta de Giribaile, en esta última etapa de la historia.

Los factores físicos y culturales considerados proporcionan algunas de las claves para interpretar, correctamente, la naturaleza del registro arqueológico sobre la superficie del terreno de Giribaile. La ocupación del espolón más septentrional de la meseta durante varios momentos históricos, parece condicionada por su posición de dominio sobre los valles circundantes. La pérdida del interés por ejercer este control geoestratégico explica los sucesivos períodos de abandono. Por el contrario, las condiciones geológicas de la meseta la convierten en un terreno de bajo rendimiento agrícola y poco apto para la práctica de la agricultura. Esos recursos se obtienen de la puesta en explotación de las fértiles tierras del valle o de las huertas cercanas, en la base del farallón de roca, variable dependiente del tamaño de la comunidad y de sus necesidades de generar un excedente. De todo ello se deduce que la dinámica histórica de Giribaile está marcada por una sucesión de períodos de ocupación, intensos, pero de duración limitada, que alternan con momentos de abandono casi absoluto, debido a las restricciones productivas que impone la propia naturaleza del terreno.

Hechas todas estas consideraciones, a diferencia de lo que suele suceder habitualmente, no parece ser el cultivo de estos terrenos o las actuacio- 
nes de transformación del espacio relacionadas con procesos de especulación los principales factores a considerar entre los procesos postdeposicionales que han afectado a las sucesivas superficies de exposición de los materiales, ni tampoco un régimen sedimentario, sino los procesos naturales asociados a la propia erosión del terreno. Resulta determinante en este sentido la utilización de la topografía para la interpretación de las distribuciones de materiales a partir de la lectura de las principales líneas de desplazamiento de estos a lo largo y ancho de la meseta de Giribaile.

Un último factor relevante en la historia geológica reciente de esta área arqueológica tiene que ver con los cambios de magnitud de los procesos de alteración naturales, vinculado a la propia estructura geológica de la meseta que periódicamente sufre el desprendimiento de grandes masas de roca que se desgajan del farallón. Al terremoto de Lisboa de 1755 se asocia, posiblemente, el desprendimiento del frente del Complejo Rupestre 4 y, tal vez, también el hundimiento de parte de la bóveda de la cueva-santuario de época ibérica. Recientemente, un desprendimiento de menor envergadura ha afectado a una parte del frente exterior del Complejo Rupestre 3, inutilizando el acceso a través de uno de los cortijos. Estos procesos, sin embargo, tienen lugar a una escala superior a la considerada en este estudio, pero pudo tener que ver en el pasado con el desmoronamiento de parte de la fortificación perimetral que rodeaba el oppidum de Giribaile, especialmente si tomamos como referencia su flanco sureste.

\subsubsection{Factores relacionados con el método de trabajo}

Pensamos en el propio diseño de la prospección, con los objetivos y con los medios disponibles, tanto técnicos como de capital humano, los cuales definen aspectos de gran importancia para garantizar la calidad de los trabajos. Citamos entre estos la existencia o no de controles de densidad, el tamaño, la forma y la distribución de las unidades de muestra, la precisión en su localización sobre el terreno, la forma de recolección, las condiciones de observación relacionadas con las circunstancias superficiales del terreno y las variaciones en la exposición a la lluvia, la cualificación del personal y el tamaño del equipo, etc.
Todos estos aspectos son los que conforman el protocolo de trabajo.

\section{PROTOCOLO DE TRABAJO}

La microprospección en la meseta de Giribaile ha proporcionado una oportunidad única para la puesta a punto del método de registro de superficie que comenzamos en la intervención arqueológica en el santuario ibérico de El Pajarillo y que también habíamos aplicado en otros oppida de la provincia de Jaén, entre ellos, Cerro Alcalá, antigua capital de la Osigitania, transformada, posteriormente, en la ciudad romana de Ossigi Latonium (Lozano y Gutiérrez 2006). La experiencia acumulada se unía a las características, ya comentadas, que ofrecía Giribaile y a las propias condiciones del estudio, para convertir este proyecto de investigación en un auténtico laboratorio, en el escenario ideal para experimentar, definir y estandarizar los detalles de un protocolo de trabajo (Fig. 3).

El protocolo adaptado para la microprospección en la meseta de Giribaile incluye tres fases principales: la planificación previa, la fase de muestreo y registro, y el posterior trabajo con los materiales. Todas ellas incluyen trabajos de campo y de laboratorio organizados en paralelo y ejecutados, en ocasiones, al mismo tiempo. Aquí comentaremos los aspectos principales de los dos primeros momentos, abordando los aspectos metodológicos que fundamentan los posteriores análisis e interpretaciones históricas.

\subsection{Trabajos preparatorios y de planificación}

Los trabajos de topografía previos permitieron conocer la superficie exacta que ocupaba el oppidum, 14,56 ha, y organizar la distribución de los estratos sobre los que íbamos a realizar el muestreo. Contamos no sólo con un documento topográfico actualizado, sino también con una parcelación precisa del terreno, mediante la colocación de estacas de madera, clavadas a una equidistancia de $50 \mathrm{~m}$. En esta ocasión, a diferencia de trabajos anteriores, como los llevados a cabo en El Pajarillo o en Cerro Alcalá, carecíamos de plantaciones de olivos que definieran artificialmente los estratos sobre los que poder organizar el mues- 


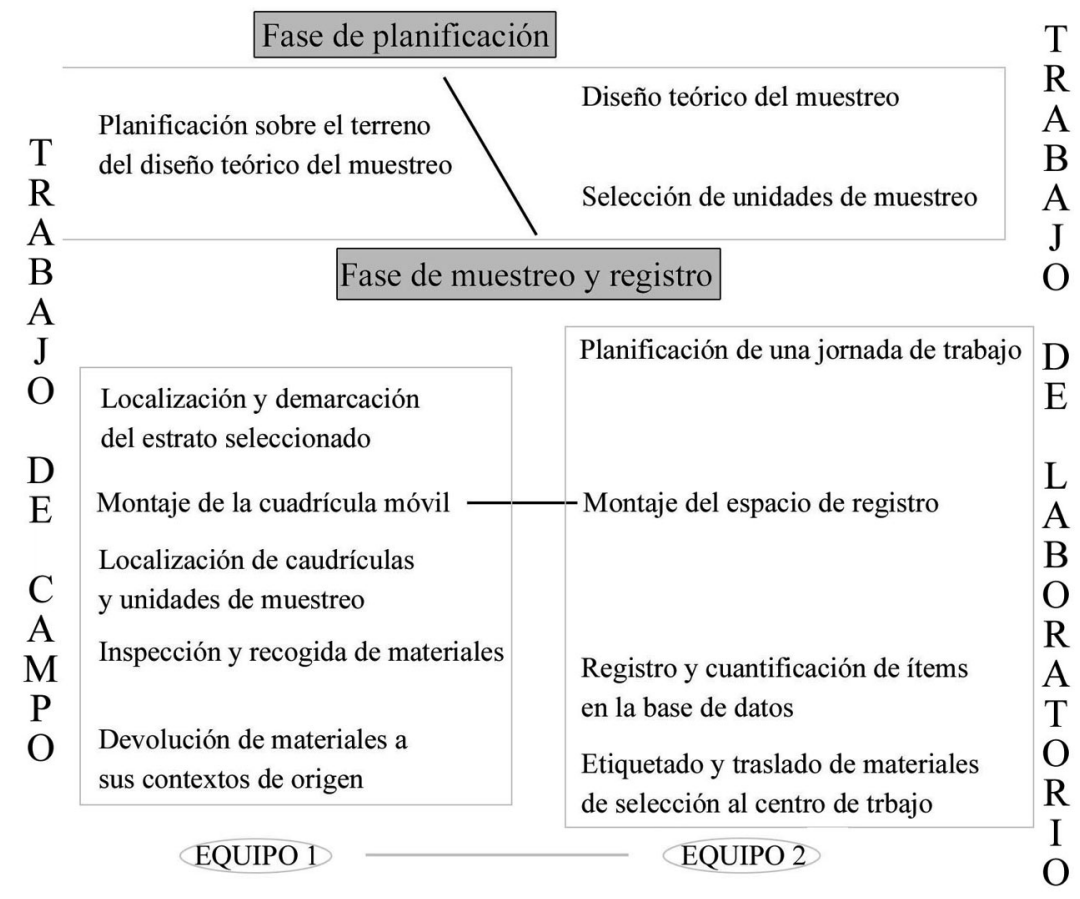

Fig. 3. Protocolo de trabajo.

treo. Dada la escasez de suelo, su poca productividad y la abundancia de piedra sobre el terreno, se había destinado a pasto para los rebaños de ovejas que, habitualmente, tenían los establos en las cercanas cuevas de Giribaile. Este espacio había quedado inculto, como un erial, en el que crecía una vegetación arbustiva, de manera espontánea, mucho más desarrollada en la Plataforma Norte, ya que las retamas, en ocasiones, llegan a superar el metro de altura, frente a la Plataforma Principal, un espacio despejado y abierto, óptimo para el desarrollo de una actividad de microprospección al proporcionar en un régimen erosivo una alta visibilidad de cerámicas en la superficie del terreno expuesta, sólo obstaculizada por la importante acumulación de piedra que se concentra en el sector que ocupa el poblado intramuros.

El primer paso consistió en la designación de un origen de coordenadas. Para facilitar el trabajo decidimos que éste se situara en el extremo sureste del dispositivo de tipo barrera, el tramo monumental de la fortificación ibérica que sirve de límite a la ciudad. Este punto favorecía que todas las unidades de muestra quedaran incluidas en valores positivos del eje de abcisas y ordenadas.

La empresa de topografía contratada se encargó de los trabajos previos de organización del es- pacio. Estos consistieron en la colocación sobre el terreno de estacas de madera cada $50 \mathrm{~m}$, formando una rejilla que cubría todo el asentamiento, ajustada al diseño teórico que se había proyectado, utilizando la cartografía analítica. Las estacas se rotularon en su parte superior con la distancia en metros respecto al origen de coordenadas en valores de X e Y. Es decir, se estableció un procedimiento de referencia basado en un sistema cartesiano de coordenadas relativas, complementado por la precisión centimétrica de las coordenadas absolutas UTM que proporciona un receptor GPS.

La elección de estratos artificiales definidos por un módulo con un intervalo de $50 \mathrm{~m}$ de lado se decidió en función de la experiencia previa en esta clase de trabajos. Permitía distribuir el espacio total en unidades de superficie de un cuarto de hectárea que se adaptaban bien a los ritmos del trabajo de campo con el equipo disponible y podían ser subdividas a su vez, fácilmente, utilizando cintas métricas. Además, cumplía el principal requisito, ya que actuaba como un múltiplo de la modulación más frecuente empleada en los olivares de Jaén, el cuadro de $10 \mathrm{~m}$ de lado. El objetivo último era adaptar la cuadrícula del terreno al módulo utilizado habitualmente, de modo que los 
trabajos de microprospección arqueológica en Giribaile fueran comparables a los realizados en otros sitios. Los estratos sólo sirven como referencia topográfica sobre el terreno, mientras que las cuadrículas constituyen la unidad de base del registro, de modo que la superficie del oppidum debe entenderse como una rejilla continua de cuadrículas, cada una identificada con un número de serie comprendido entre el 1 y el 1.357. Un sistema de registro como este, basado en un muestreo intensivo, a partir de la utilización de unidades de registro pequeñas, asegura una buena estructura de la información sobre los patrones de artefactos y garantiza posteriores tratamientos estadísticos de las series de datos.

Una vez establecida la forma y el tamaño de los estratos y su distribución sobre el terreno se realizó la selección de las unidades de muestreo. La selección de la muestra se llevó a cabo utilizando un método sistemático. Usamos una tabla de números aleatorios de dos cifras generada por ordenador con un intervalo comprendido entre el 00 y el 99 , de modo que cada elemento individual en la población tuviera las mismas oportunidades de ser elegido y que la inferencia estadística fuera lo más fiable posible. A diferencia de la intervención realizada en El Pajarillo, se decidió recoger y procesar una fracción muestral del $1 \%$, es decir, seleccionar una cuadrícula de cada 100, como habíamos hecho en la mayor parte de los oppida muestreados en la provincia de Jaén hasta ese momento. El tamaño de la unidad de muestreo y de la fracción muestral depende de la extensión del sitio y de la densidad de artefactos. La fracción muestral deberá aumentar a medida que decrece el tamaño del sitio, asegurando la recogida de una colección de artefactos suficiente. En Giribaile la densidad de la ocupación y la gran superficie del área arqueológica que iba a ser muestreada favorecía la calidad de los resultados, ya que las poblaciones numerosas de artefactos, además de mejorar la calidad de la inferencia estadística, aumentan las posibilidades de que las colecciones de superficie proporcionen muestras representativas de las frecuencias de clases (Lewarch y O’Brien 1981).

\subsection{La fase de muestreo $y$ el registro}

En total, en la meseta de Giribaile fueron muestreadas 1.357 cuadrículas, cuya extensión,
13,57 ha, resulta algo menor que la del asentamiento por dos motivos. La zona comprendida dentro del recinto amurallado del castillo impedía reproducir las condiciones de muestreo con cuadrícula móvil adoptadas en el resto de la meseta. En segundo lugar, la propia forma y el contorno irregular de la meseta debía compatibilizarse con la geometría (cuadrada) de las unidades de muestra.

El trabajo concreto para una jornada se planificaba con suficiente anticipación, considerando variables como el número y cualificación de los prospectores o las condiciones de visibilidad y accesibilidad del terreno: densidad de la vegetación en esa zona, condiciones climatológicas previstas para ese día, grado de humedad de la tierra, presencia de obstáculos tales como acumulaciones de piedra, muros, zonas en depresión, etc. Se intentaba llevar a cabo un diseño realista de objetivos, organizando los recorridos en el campo de modo que se rentabilizaran esfuerzos (Fig. 4).

Para aminorar, en lo posible, problemas relacionados con la variabilidad en las condiciones de luminosidad ambiental, la prospección daba inicio a la misma hora y tenía una duración, aproximadamente, equivalente (Shennan 1985: 39). Cada jornada comenzaba localizando la estaca que se tomaba como punto de referencia inicial y se unían con cintas métricas las estacas que daban forma al espacio de $50 \times 50 \mathrm{~m}$ que debía ser muestreado (2). El equipo de trabajo se dividía en dos grupos. Uno montaba la cuadrícula móvil, mientras que el otro instalaba un pequeño laboratorio de registro de campo con un ordenador portátil y una balanza, a los que daba servicio un grupo electrógeno con una autonomía en torno a las seis horas (Lám. IV). Estos dos equipos trabajaban distintos aspectos del registro, en paralelo y coordinados. La ubicación del espacio de registro, instalado en uno de los lados del estrato, tenía en cuenta la zona a prospectar prevista para minimizar los recorridos.

La mayor dificultad del muestreo (Fig. 5) consistía en la localización espacial de las unidades que debían ser muestreadas a partir de los gran-

(2) Este espacio ha sido denominado "estrato" y hace referencia a una unidad de superficie homogénea que da sentido al muestreo arqueológico. Estos "estratos" de muestreo tienen un carácter artificial, frente a los criterios de estratificación naturales, basados habitualmente en una interpretación geográfica, que suele emplearse en prospecciones arqueológicas de escala regional. 


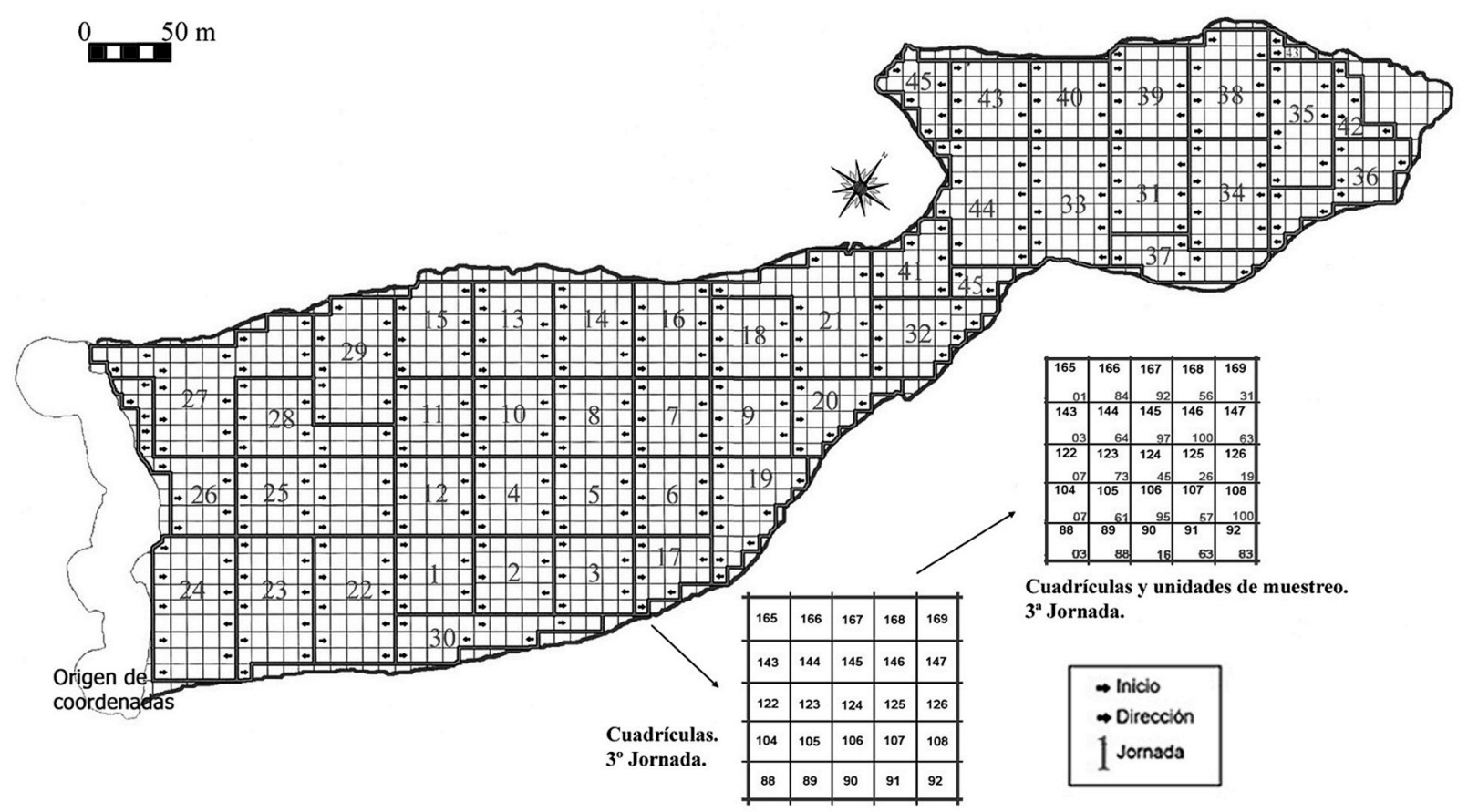

Fig. 4. Organización de las jornadas de trabajo en Giribaile (Vilches, Jaén). Ejemplo de distribución de estratos, cuadrículas y unidades de muestra.

des estratos. Éstos se dividían con cintas métricas, en cinco transect de $10 \mathrm{~m}$ de ancho, subdividiéndose a su vez en cuadrículas de $10 \times 10 \mathrm{~m}$, equivalentes al módulo formado por los cuadros que forman los olivos y facilitando el uso de la cuadrícula móvil, en su versión de mayor tamaño.

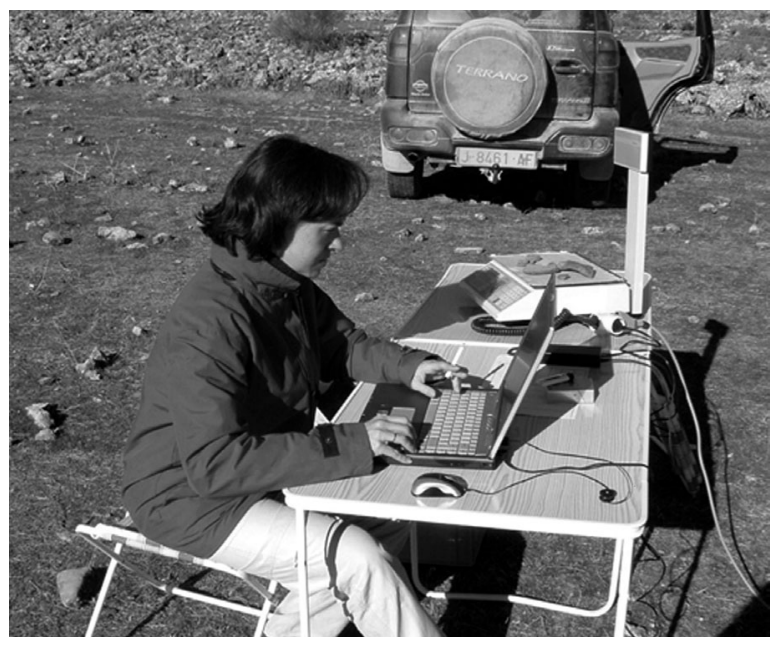

Lám. IV. Meseta de Giribaile (Vilches, Jaén). Laboratorio de campo.
Como las cuadrículas de muestreo eran de $100 \mathrm{~m}^{2}$ y la cuadrícula móvil abarcaba como máximo 25 $\mathrm{m}^{2}$ cada una de ellas podía subdividirse teóricamente sobre el terreno en cuatro cuadrantes.

Finalizados los trabajos de localización espacial, los prospectores recogían los materiales en la unidad de muestreo seleccionada, siguiendo los criterios fijados en la intervención de microprospección en El Pajarillo. Una vez concluido este primer reconocimiento de superficie, un prospector trasladaba los materiales al espacio de registro, concentrándose los demás en la cuadrícula de $10 \times 10 \mathrm{~m}$. Cada uno realizaba la inspección visual de un cuadrante y recogía sólo el material de selección (formas cerámicas reconocibles, fragmentos decorados, etc.) que fuera capaz de identificar sobre el terreno bajo la dirección de un experto para evitar problemas en el grado de reconocimiento de los materiales (Haselgrove 1985: 23). La figura 6 muestra la intensidad de la prospección en número de personas-día por unidad de área inspeccionada.

En el laboratorio de campo los ítems que procedían de las unidades de muestra eran cuantificados en la base de datos, separando los que consideramos materiales de selección. Los fragmentos de cerámicas sin información espe- 
Tamaño del asentamiento: 14,56 ha

Superficie muestreada: 13,57 ha

ESCALA DE TRABAJO

(cobertura total dentro del asentamiento)

TIPO DE PROSPECCIÓN

(intensiva de carácter sistemático)

Estratos: $50 \times 50 \mathrm{~m}$
Cuadrículas: $10 \times 10 \mathrm{~m}$
Cuadrtantes: $5 \times 5 \mathrm{~m}$
Unidades de muestreo: $1 \times 1 \mathrm{~m}$

CARACTERÍSTICAS DEL MUESTREO

(aleatorio, estratificado, sistemático, no alineado)

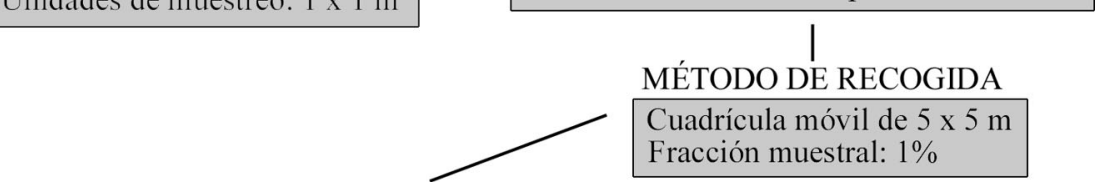

EQUIPOS DE TRABAJO

Número y cualificación de los prospectores: 4-6 personas

(equipo fijo + alumnos en prácticas)

Fig. 5. Esquema de muestreo, con inclusión de la forma y el tamaño de las unidades de reconocimiento del terreno en la meseta de Giribaile (Vilches, Jaén).

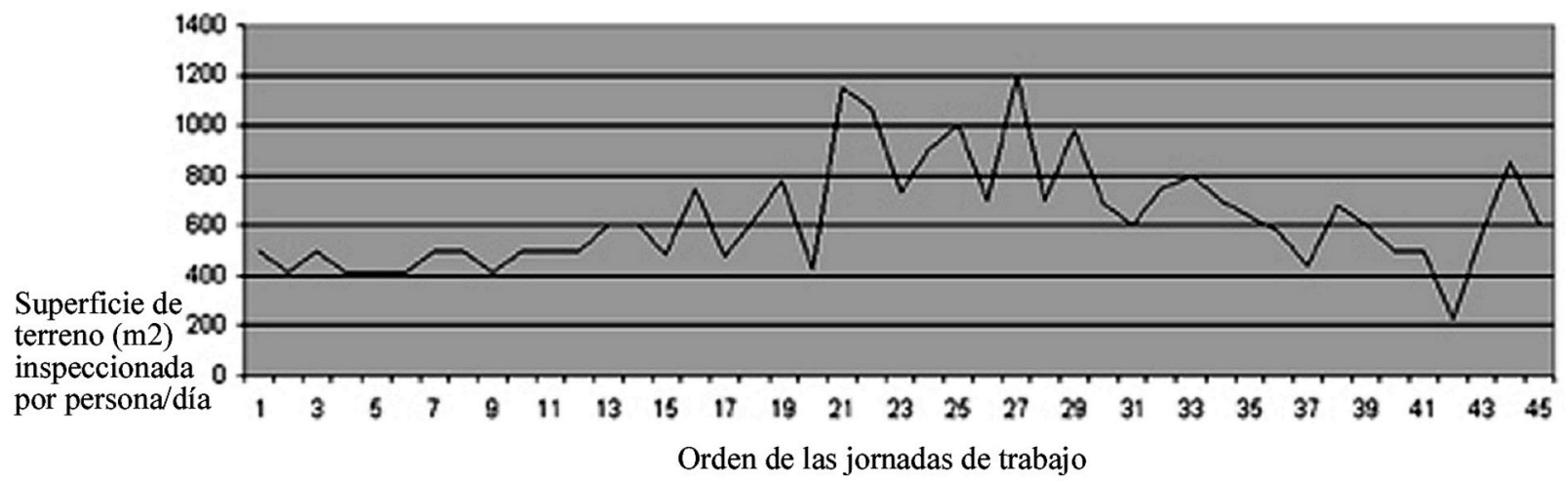

Fig. 6. Microprospección en Giribaile (Vilches, Jaén). Control de calidad. El eje de abcisas indica la superficie de terreno inspeccionada $\left(\mathrm{en}^{2}\right.$ ) por persona/día, el eje de ordenadas las jornadas de trabajo.

cialmente relevante, una vez contados, pesados y clasificados, eran devueltos a su lugar de origen. Los primeros se introducían en bolsas etiquetadas para ser trasladados al Centro Andaluz de Arqueología Ibérica.

El registro en la base de datos se organizó a partir del número de las cuadrículas y de sus unidades de muestra. De este modo los ítems no son considerados individualmente sino formando parte de pequeños agrupamientos o clusters de pie- zas que toman como referencia unidades espaciales, de tamaños diversos, dentro de la rejilla de muestreo, tratándose de una información que hace referencia al contexto del estrato. Así, las distribuciones de densidades de materiales en superficie que se presentan en las figuras 7 a 9, son el resultado de una sencilla representación que generaliza los valores obtenidos en el muestreo a toda la cuadrícula. Para su realización no se ha utilizado ningún método de interpolación, aunque 
sería posible el tratamiento y posterior procesamiento de los datos, utilizando las capacidades que ofrecen los SIG al uso. Por el momento, las representaciones incluidas en el presente artículo se limitan a conectar la información temática resultante de tratar estadísticamente las variables de modo independiente, generalizando esa información contextual obtenida en $1 \mathrm{~m}^{2}$, como una mancha de color que ocupa la totalidad de la superficie de la cuadrícula.

Con la intención de causar el mínimo impacto sobre el área arqueológica y trasladar la menor cantidad de material posible se gestionó durante la fase de campo de la prospección la mayor parte del trabajo que, habitualmente, se viene llevando a cabo en el laboratorio. Esta experiencia resultó altamente positiva ya que permitía procesar un gran volumen de información in situ y devolver una importante cantidad de fragmentos de cerámica a sus contextos de origen. La localización exacta de sus unidades de procedencia permite superar la clásica polémica acerca de si éstos se deben recoger o no durante los trabajos de campo y ajustarse al criterio de transportar sólo los imprescindibles, siguiendo procedimientos de recogida adecuados (Fasham et al. 1980: 3).

Siempre las dos mismas personas se encargaban del registro, para reducir, en la medida de lo posible, la subjetividad en los criterios de clasificación. Entre éstos se incluye una escala relativa de tamaños para valorar los fragmentos de cerámica. Resulta de la aplicación de un procedimiento extremadamente sencillo y útil para cuantificar en un tiempo breve un número elevado de ítems. Se toma como medida significativa el eje máximo de cada pieza a partir de una escala de intervalos que comienza con un cuadrado de $2 \mathrm{~cm}$ de lado y crece en progresión aritmética. El fragmento cuyo eje máximo queda incluido en el primer cuadrado pertenece al tamaño 1 y así sucesivamente.

\section{INTERPRETACIÓN DE LA DISTRIBUCIÓN DE MATERIALES DE SUPERFICIE EN GIRIBAILE}

Los resultados obtenidos al finalizar los trabajos de microprospección confirmaron, en parte, el esquema general conocido a priori sobre la ocupación de la meseta de Giribaile. Además permitieron precisiones cronológicas de gran importancia, como que la destrucción del oppidum ibé- rico debería llevarse al final del siglo III a.C., en el marco de los conflictos que marcan la Segunda Guerra Púnica, frente a la hipótesis tradicional que identifica Giribaile con la ciudad ibérica destruida hacia el año 90 a.C. por el tribuno romano Quinto Sertorio, acción narrada por Plutarco (Sertorio, III, 5-10). El conjunto de materiales que podrían asociarse al horizonte de finales del siglo II a.C. - principios del siglo I a.C. es un grupo muy reducido de fragmentos compuesto por una posible imitación de cerámica campaniense y un ánfora barnizada exteriormente de negro, al que debe sumarse, posiblemente, un ungüentario depositado en el Museo Arqueológico de Granada y perteneciente a la colección Gómez Moreno.

Más difícil resulta caracterizar y establecer la verdadera entidad del primitivo poblado de cabañas de la Edad del Bronce. Al ser los materiales más antiguos de la secuencia también son, teóricamente, los menos representados en las colecciones de superficie, aunque habría que tener cuidado con esta clase de afirmaciones. Como demuestran varios trabajos clásicos del microespacio en prospección de superficie, la recuperación de materiales procedentes de las ocupaciones más tempranas puede aumentar de existir reocupaciones posteriores localizadas directamente sobre ella, aflorando materiales a través de los propios procesos culturales postdeposicionales (Kirkby y Kirkby 1976). También habría que tener en consideración la potencia de la capa de derrumbe de las paredes de las casas de época ibérica que cubren los niveles correspondientes a la etapa de la ocupación del poblado de la Edad del Bronce. Según los resultados obtenidos en la excavación de los "pozos de prospección” de la Plataforma Principal, los suelos de ocupación más recientes se localizan relativamente próximos a la superficie, en ocasiones a menos de un metro. Si se compara con algunos estudios experimentales realizados en este sentido, como los citados de Kirkby y Kirkby (1976), no parece una profundidad suficiente para ocultar completamente los depósitos de materiales más antiguos. Es decir, la disimetría en la frecuencia de aparición de materiales pertenecientes al poblado de la Edad del Bronce entre la Plataforma Principal y la Plataforma Norte, claramente favorable a esta última, en principio y a falta de excavaciones que puedan confirmar esta hipótesis, debe entenderse como una imagen real sobre la entidad del primitivo poblado de cabañas (Fig. 7). 


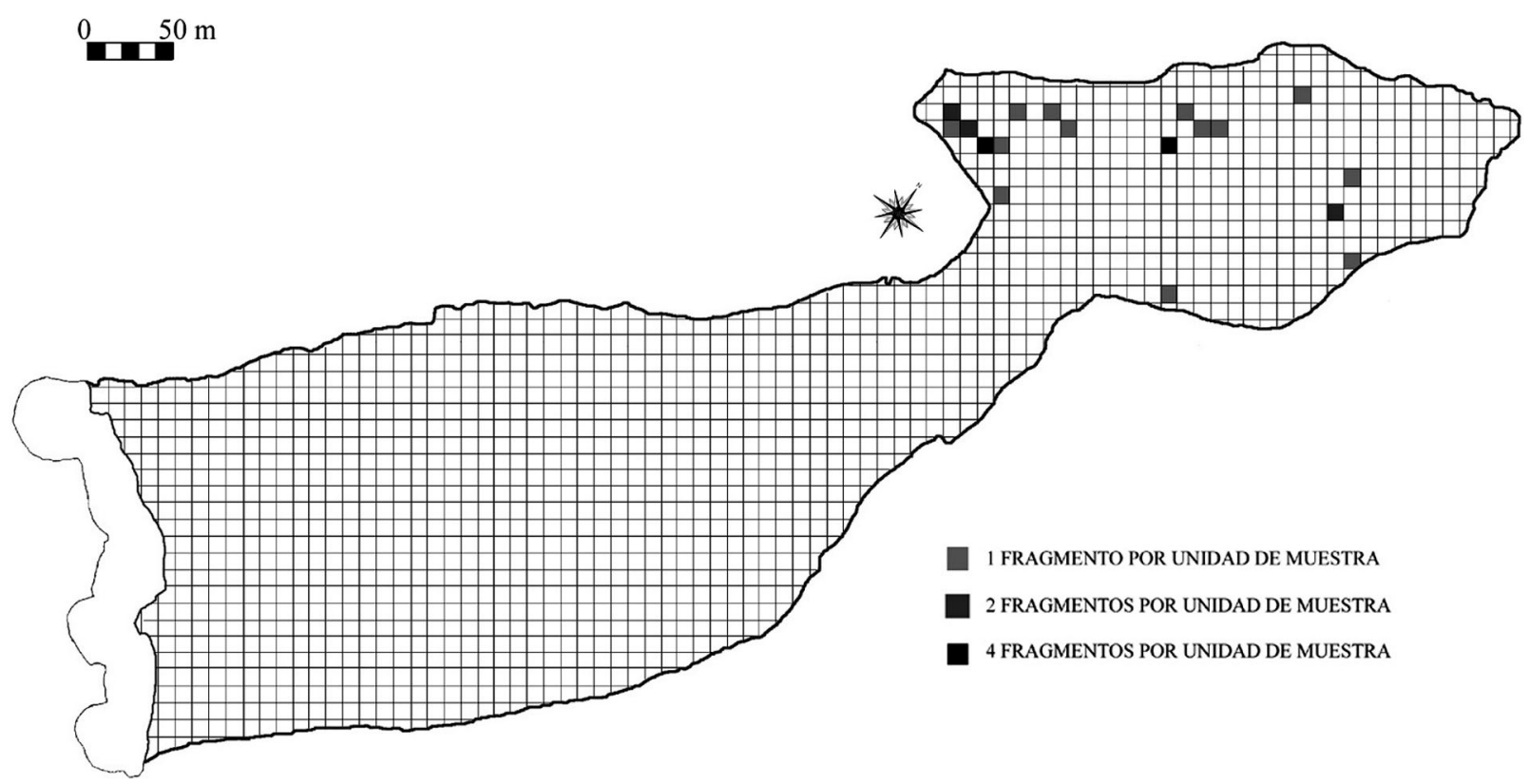

Fig. 7. Microprospección en Giribaile (Vilches, Jaén). Cerámicas de la Edad del Bronce: número de piezas $/ \mathrm{m}^{2}$.

Otra cuestión diferente sería valorar la representatividad porcentual, por frecuencia de clases, de los materiales pertenecientes a esta fase prehistórica en superficie respecto a los depósitos que aún permanecen enterrados, pero el mayor número de evidencias de este poblado se concentra en la Plataforma Norte, donde carecemos de referencia sobre la entidad de los depósitos arqueológicos, ya que nunca se ha excavado en esta área. Las apreciaciones a partir del análisis topográfico parecen indicar la presencia de depósitos sellados desde antiguo en el espacio comprendido entre el afloramiento de roca que separa la Plataforma Principal de la Plataforma Norte y la vaguada que antecede al castillo. Por último, resulta significativo observar cómo una gran parte de los materiales representados en superficie, pertenecientes a esta fase de ocupación inicial proceden de una expoliación localizada en el ángulo Noroeste de la Plataforma Norte y aparecen prácticamente en superficie, al nivel actual del terreno.

Además, la campaña de microprospección ha permitido reconocer una etapa poco estudiada en la ocupación de la meseta, a partir de un conjunto de cerámicas que posiblemente haya que situar en los siglos VIII-IX d.C., repartidas por la mayor parte de la extensión de la zona arqueológica prospectada. Estas cerámicas, sin duda, deben asociarse a la ocupación de las cuevas. La reciente campaña de prospección ha vuelto a recordar- nos que la historia de Giribaile se ha escrito, desde siempre, a partir de la lectura complementaria de dos escenarios principales, la meseta y las cuevas. Por ejemplo, hoy apuntamos la presencia de una posible cueva-santuario asociada a la ciudad ibérica, del mismo modo que una ocupación del siglo IX d.C. en la meseta debe entenderse con relación a la primitiva comunidad de eremitas que habitó las cuevas.

Uno de los principales problemas analíticos para la utilización de las colecciones de materiales de superficie en el área arqueológica de Giribaile ha sido determinar con exactitud la antigüedad de un conjunto de cerámicas de aspecto grosero, realizadas a torno lento, de las que no teníamos referencias cronológicas exactas a partir de conjuntos bien contextualizados en excavaciones arqueológicas. Estos fragmentos de cerámica, numerosos en la meseta de Giribaile y que actuaban como un ruido de fondo constante, fueron analizados a través de la técnica de datación absoluta por termoluminiscencia (3).

(3) Los análisis fueron realizados por el Laboratorio de Datación y Radioquímica de la Universidad Autónoma de Madrid y sitúan el último calentamiento enérgico de estos materiales de manera coetánea. El primero tendría lugar hace $1115 \pm 118$ años B.P. (muestra M-371) y el segundo hace $1142 \pm 69$ años B.P. (muestra M-821), lo cual lleva a datar la fabricación de las muestras estudiadas en el siglo IX d.C. 
Finalmente, la campaña de microprospección arqueológica ha permitido una primera valoración de la ocupación islámica de la meseta de Giribaile, más allá de las consideraciones realizadas hasta el momento a partir de los restos monumentales conservados del castillo. La comparación para esta fase de los resultados obtenidos del muestreo y de la recogida general de materiales por cuadrícula refleja, en general, una imagen coincidente por lo que respecta a la consideración del área nuclear que se extiende por una buena parte de la Plataforma Norte. Sólo la presencia puntual de fragmentos de cerámica vidriada en la Plataforma Principal marca una diferencia relevante.

Los momentos menos representados en la cultura material de la meseta se definen por la escasa presencia de cerámica romana Altoimperial, ya que tan sólo fue posible documentar dos únicos fragmentos de terra sigillata, hispánica. Estos habría que unirlos a algunos pequeños trozos recogidos en visitas anteriores también en el mismo sector, junto al dispositivo de tipo barrera, a otro fragmento localizado en 1986 durante la campaña de limpieza y a algunos fragmentos de cerámica común romana y de terra sigillata (García-Gelabert 1988: 418), sin concretar más datos. En total podría tratarse de menos de una decena de fragmentos de tamaño 1, siguiendo nuestra propia clasificación (Gutiérrez 2002: 91-92), concentrados todos ellos en la Plataforma Principal, más concretamente en la zona próxima al poblado intramuros y al dispositivo de tipo barrera. Estas dispersiones de baja intensidad (4) deben ponerse con relación a algunos asentamientos rurales que se reparten por la ladera sureste de la meseta de Giribaile y con actividades asociadas a dichos establecimientos, posiblemente vinculadas a la puesta en explotación del saltus, aunque resulta difícil concretar más por el momento. La cantidad total de fragmentos recogida, aunque no se puede cuantificar con exactitud, muestra que estos terrenos registran durante el período tratado una actividad productiva limitada.

Seguimos la línea de ponderar la entidad de los hallazgos de cerámicas de vajilla de calidad dentro de su contexto, con relación a las producciones mayoritarias, y no sobreestimarla como indicado-

(4) Identificadas de forma habitual en prospecciones de urgencia como las llevadas a cabo en diversas lomas del entorno urbanizable de la ciudad de Jaén. res del estatus de un sitio determinado (McDonald 1995). Resulta muy diferente la lectura a partir de dos pequeños fragmentos de cerámica ática del siglo IV a.C. en la meseta de Giribaile. Numéricamente repiten la frecuencia de aparición de los fragmentos de terra sigillata y también presentan contextos de localización espacial parecidos, si bien su proximidad relativa implica diferencias muy importantes relacionadas con el estudio de la cultura material. Los fragmentos de terra sigillata constituyen hallazgos excepcionales interpretados con relación al conjunto de los materiales repartidos en superficie en la meseta de Giribaile, mientras que la mayor parte de las cerámicas claras documentadas en superficie son contemporáneas o inmediatamente posteriores a los fragmentos de cerámica griega importados. Al respecto resulta también importante apuntar el carácter singular de esta presencia en la ciudad ibérica, en contraste con lo que sucede con las necrópolis del oppidum, que se localizan rodeando la base sobre la que se levanta la meseta de Giribaile.

También resulta complicado establecer la entidad de los procesos de reutilización y reocupación de las viviendas y el trazado urbano de época ibérica por parte de la comunidad que se instaló en las cuevas y en la meseta de Giribaile en un momento difícil de precisar a caballo entre el mundo tardoantiguo y la alta Edad Media. El oppidum fue destruido de una forma violenta, pero el largo período de tiempo transcurrido y la utilización de una arquitectura de tierra favorecía su ocultamiento, resultando aventurado definir el grado de visibilidad de la antigua ciudad ibérica. Por otra parte, esta clase de hisn a menudo proporciona un registro arqueológico marcado por la abundancia de materiales cerámicos acumulados en grandes fosas que actúan como silos, almacenes, basureros, etc. (Salvatierra et al. 2007), sin correspondencia en la entidad de su arquitectura, ya que, a menudo, el hábitat se organiza a partir de unidades de vivienda construidas con materiales orgánicos y sólo ocasionalmente se recurre al uso de la piedra. Esta nueva fase de reocupación del solar de la antigua ciudad ibérica ha podido afectar al registro de superficie, como una distorsión cultural de carácter postdeposicional, sobre todo a partir de la excavación de fosas, incorporando materiales enterrados a las colecciones de superficie.

Las dos variables principales consideradas en el estudio de las distribuciones de materiales en 
superficie de las que derivan las interpretaciones sobre la secuencia son el número total de fragmentos (Fig. 8) y su peso por unidad de muestreo. Estas reflejan una distribución aparentemente homogénea y regular a lo largo de la mayor parte del desarrollo de las dos plataformas y concentraciones puntuales que responden a acumulaciones que en ocasiones se explican por las pendientes propias del terreno. Estas dos variables presentan un alto grado de correlación, confirmando las apreciaciones empíricas de M. Millet (2000a: 54) que la sitúa por encima del $90 \%$. De todos modos, tal y como indica el propio M. Millet, tener en cuenta ambas variables en los estudios de microespacio permite estimar el número total de recipientes de cerámica y el índice EVE (Estimated Vessel Equivalent), aunque estos sean más aconsejables para el tratamiento estadístico de conjuntos procedentes de excavación, además de poder evaluar posibles variaciones en los resultados derivadas de la utilización de ambos métodos.

Para comprender, correctamente, la naturaleza del registro arqueológico en Giribaile deben tenerse en cuenta, en primer lugar, los factores culturales relacionados con la historia particular de la ocupación de esta meseta. Especialmente, interesan las características de la arquitectura utilizada en época ibérica, por el uso frecuente en las casas de paredes de tapial y adobes, levantadas sobre zócalos de piedra bajos. El desmoronamiento de las paredes en un incendio generalizado que pone fin a la etapa de la ciudad ibérica, según los informes de las antiguas campañas de excavación, inició el proceso de formación de este sitio arqueológico en toda su extensión. La fase anterior de ocupación, correspondiente al poblado de cabañas de la Edad del Bronce, parece mucho más limitada espacialmente. De igual modo, las ocupaciones que sucedieron a la ciudad ibérica no parecen haber dejado un nivel de arquitectura relevante, comparable con el de las construcciones del oppidum, a excepción del castillo que ocupa un espacio acotado en el espolón noreste.

Al respecto, Hesse (1971) hace una primera llamada de atención sobre el hecho de que la erosión de las paredes incrementa las concentraciones de artefactos en superficie. Este aspecto fue desarrollado posteriormente en un estudio específico por Kirkby y Kirkby (1976), trabajando sobre los efectos causados por la descomposición de paredes de adobes en medios semiáridos. La cuestión no resulta baladí en nuestro caso. Los trabajos de excavación en el oppidum de la Plaza de Armas de Puente Tablas (Jaén) pusieron de manifiesto cómo la abundancia de pequeños frag-

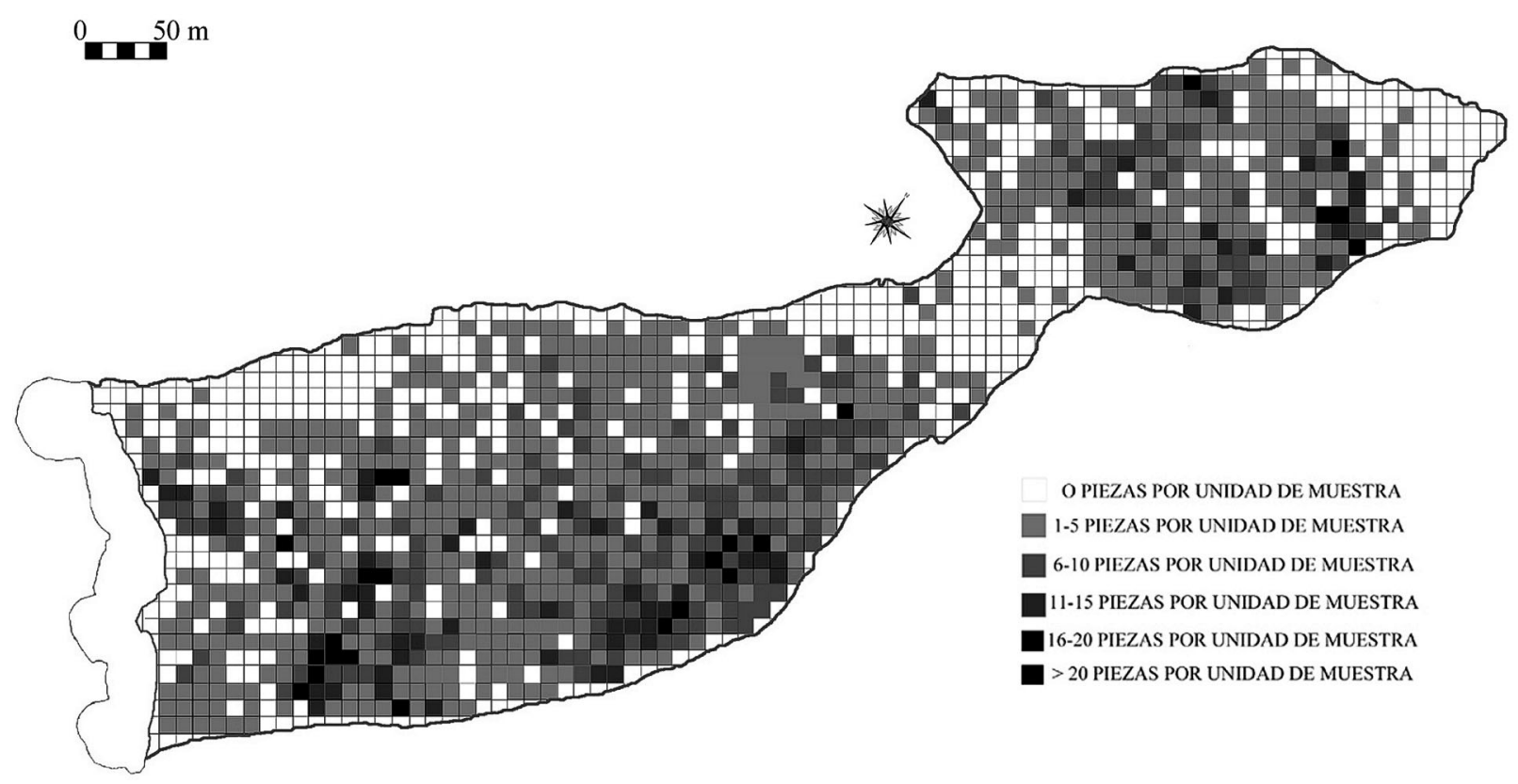

Fig. 8. Microprospección en Giribaile (Vilches, Jaén). Número de piezas $/ \mathrm{m}^{2}$. 
mentos de cerámica incluidos en los tapiales dificultaba sobremanera la lectura de los registros microespaciales de estos niveles, cuyas distribuciones eran aparentemente caóticas o aleatorias. En cambio, al alcanzar los suelos de las viviendas era posible definir las áreas de actividad a partir de la distribución de los conjuntos cerámicos.

La falta de estudios experimentales sobre el tamaño y la cantidad de fragmentos de cerámica que pudieron contener las paredes de tierra en Giribaile y el cálculo del volumen de dichos derrumbes en cada lugar concreto del yacimiento, no permite precisar cuántos de los distribuidos actualmente en la superficie del terreno formaron parte de los tapiales, pero sí que una gran parte de los más pequeños, especialmente los de tamaño 1 (Fig. 9), son resultado de la caída de las paredes. Estos fragmentos, pertenecientes a recipientes rotos o en desuso, fueron reutilizados como material de construcción, aumentando la resistencia de los tapiales.

Por otra parte, según los estudios sobre el "efecto-tamaño" de Baker (1978) las cerámicas de mayor tamaño (en Giribaile a partir del tamaño igual o mayor que 3) estarían sobrerrepresentadas en las colecciones de superficie, como consecuencia de los procesos de cultivo del terreno, ya que el desplazamiento vertical de los fragmentos de cerámica aumenta en los procesos de cultivo iniciales, aunque éstos sean limitados como ocurre en el caso de la meseta de Giribaile, y continua de forma más atenuada con sucesivos arados (Ammerman y Feldman 1978). Al mismo tiempo, siguiendo a Baker (1978), los fragmentos de menor tamaño son menos interesantes para establecer estimaciones sobre el volumen de los que aún permanecen enterrados.

Las características geológicas y geomorfológicas de Giribaile han de tenerse en cuenta para la correcta interpretación de las distribuciones de superficie que constituye el registro analizado a lo largo del otoño de 2004 y parte de la primavera de 2005. Los trabajos de topografía han resultado fundamentales, ya que han establecido con claridad las principales líneas de erosión a través de las cuales se desplazan los materiales. De todos modos, la conclusión última del análisis de Kirkby y Kirkby (1976) es que en un medio semiárido, con un régimen erosivo de vegetación bajo, características similares a las que presenta actualmente la meseta de Giribaile, el movimiento de las cerámicas a través de la superficie del terreno tiene un efecto limitado.

La mayor parte de las distribuciones de superficie, comenzando por la densidad del número de piezas $/ \mathrm{m}^{2}$, presentan una importante concentración de cerámicas hacia el reborde sureste de la meseta, en la Plataforma Principal y en la Plataforma Norte. Aquí, el alto farallón de roca marca un límite claro e impide analizar el desplazamien-

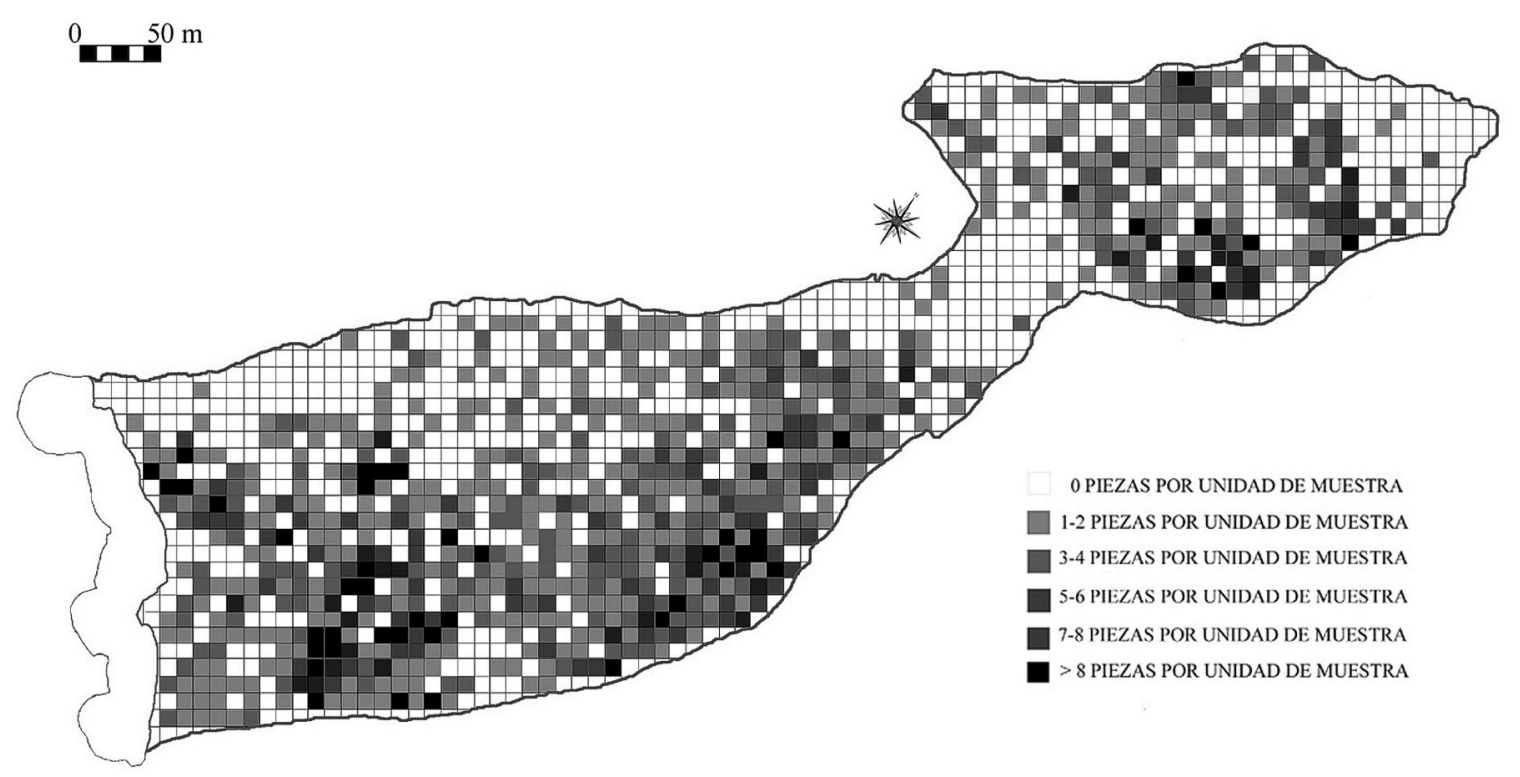

Fig. 9. Microprospección en Giribaile (Vilches, Jaén). Tamaño 1: número de piezas $/ \mathrm{m}^{2}$. 
to por gravedad de los materiales en ladera y su deposición según el grado de la pendiente, siguiendo los estudios clásicos del microespacio. Por el contrario, las empinadas laderas que se localizan por debajo de la cota en la que se ubican las cuevas, presentan importantes procesos de arrastre de materiales asociados a las fuertes pendientes y a procesos de escorrentía intensos, relacionados con las arcillas que forman la cobertura predominante en estos terrenos.

Las especiales condiciones naturales de la meseta de Giribaile limitan el efecto de los procesos geomorfológicos, tan importantes a la hora de abordar los proyectos de prospección del paisaje. Más relevancia parece tener la detención de los materiales a causa de la vegetación. Existen diferencias claras entre la Plataforma Principal, donde la vegetación es escasa, y la Plataforma Norte. Aquí, la envergadura de los arbustos puede llegar, incluso, a dificultar el paso y, por tanto, también sus raíces constituyen un obstáculo al posible desplazamiento de los materiales. Este comportamiento diferencial de la vegetación parece consecuencia del uso actual del terreno como pasto para el ganado. También el relieve de la parte central de la Plataforma Norte, que marca una cota destacada, favorece la idea de que en este lugar los depósitos se encuentran sellados, provocando un movimiento escaso de materiales cerámicos. El efecto de obstrucción y ocultamiento de vestigios por parte de la vegetación no resulta demasiado relevante dado el tipo de cobertura vegetal en la meseta y el tamaño y la entidad del sitio arqueológico.

En algunos trabajos experimentales, como el proyecto Beocia, para evitar este posible efecto negativo en la interpretación de patrones de densidad bajos o, incluso, medios se ha elaborado una escala de visibilidad entre 0 y 10 , en la cual 1 sobre 10 representa $1 \mathrm{~m}$ con buena visibilidad sobre 10 y $9 \mathrm{~m}$ oscurecidos por una vegetación que obstaculiza un correcto reconocimiento del terreno. La cuantificación de este parámetro permite corregir los datos iniciales (Bintliff 1992: 98-100).

Finalmente, hemos de apuntar que, por el momento, nos hemos centrado en el análisis e interpretación de las distribuciones de cerámicas en superficie, pero existen otras categorías de materiales que contienen en sí mismos un potencial de análisis alto, cuyo estudio deberá ser abordado en futuros trabajos. Así, las escorias pueden ser un buen indicador para profundizar en aspectos complejos de la ocupación de la meseta, como la estructura interna de sitio y la utilización de determinados espacios para actividades de producción como hornos de reducción y forjas. Las escorias podrían pertenecer a época ibérica, tal y como muestra la presencia de exvotos, pero también podrían asociarse a la ocupación medieval temprana. Las escorias, junto con otros subproductos (fallos de horno, trozos de mineral tratado, litargirios, etc.) y medios de producción (molinos, fusayolas, pondera, crisoles, paredes de estructuras de combustión, etc.) documentados, puntualmente, en la meseta de Giribaile, presentan un enorme potencial de información sobre los procesos de trabajo artesanales domésticos y especializados que tuvieron cabida dentro la ciudad ibérica. El análisis cualitativo de esta clase de evidencias permite un tratamiento general de problemas culturales complejos relacionados con el modo de vida a partir del estudio de las colecciones de superficie, más allá de la determinación de áreas de actividad concretas en posteriores trabajos de excavación arqueológica.

\section{A MODO DE CONCLUSIÓN}

En la provincia de Jaén los protocolos de trabajo expuestos en el presente artículo se están convirtiendo en una rutina habitual tanto en arqueología de investigación, pudiendo citarse los casos de Ossigi Latonium, Giribaile o, más recientemente, el Castellón de Larva (Mayoral et al. 2004), como en la arqueología de gestión, por ejemplo en La Veguilla de Úbeda (Gutiérrez et al. 2007) ya que, aunque sus respectivos objetivos son distintos, el rigor del método debe ser siempre el mismo. En este sentido sería bueno recordar que, si bien el registro de atributos de un sitio es una decisión de carácter individual, la naturaleza del proceso de registro no debería serlo. Estandarizar la información a partir de un conjunto de datos paralelos y precisos, basados en la documentación de la cultura material presente en superficie en cada sitio, resulta crítico para establecer comparaciones estadísticas significativas y hacer comprensibles las interpretaciones a otros arqueólogos que no han tenido la oportunidad de visitar o conocer, de primera mano, dichos lugares (Plog et al. 1978). El conjunto de datos, procedente de las zonas superficiales expuestas en 
las áreas arqueológicas, puede ser útil para abordar una amplia gama de trabajos de investigación sobre los Paisajes Culturales, sin recurrir a la excavación extensiva o a modelos predictivos que traten el tópico del isomorfismo entre las colecciones de superficie y los depósitos que aún permanecen enterrados. Ello es especialmente así cuando se trata de estudios regionales y la escala de trabajo permite superar los problemas relacionados con las distorsiones generadas por los procesos postdeposicionales y las propias condiciones de recogida de las colecciones, estableciendo modelos recurrentes sobre el análisis de patrones de poblamiento.

\section{BIBLIOGRAFÍA}

Alcock, S.E.; Cherry, J.F. y Davis, J.L. 1994: "Intensive survey, agricultural practice and the classical landscape of Greece". En I. Morris (ed.): Classical Greece: ancient histories and modern archaeologies. New Directions in Archaeology, Cambridge University Press. Cambridge: 137-170.

Ammerman, A.J. y Feldman, M.W. 1978: "Replicated collection of site surfaces". American Antiquity 43: 734-740.

Baker, C.M. 1978: "The size effect: an explanation of variability in surface artifact assemblage content". American Antiquity 43: 288-293.

Banning, E.B. 2002: Archaeological survey. Manuals in Archaeological Method, Theory and Technique. Kluwer Academic Plenum Publishers. Nueva York.

Barker, G. 1991: "Approaches to archaeological survery". En G. Barker y J. Lloyd (eds.): Archaeological survey in the Mediterranean region. Archaeological Monographs of the British School at Rome 2. Oxford: $1-9$.

Barker, G. 1995: "Landscape Archaeology in Italy: goals for the 1990s". En N. Christie (ed.): Settlement and economy in Italy 1500 B.C. to A.D. 1500. Papers of the Fifth Conference of Italian Archaeology. Oxbow Monograph 41. Oxbow Books. Oxford: 1-11.

Barton, C.M.; Bernabeu, J.; Aura, J.E.; García, O.; Molina, L. y Schmich, S. 2004: "Historical contingency, nonlinearity and the neolithization of the Western Mediterranean". En E. Athanassopoulos y L.A. Wandsnider (eds.): Mediterranean archaeological landscapes: current issues. University of Pennsylvania Museum of Archaeology and Anthropology. Philadelphia: 99-124.

Binford, L.R. 1964: "A consideration of archaeological research design". American Antiquity 29 (4): 425-441.
Bintliff, J.L. 1992: “Appearance and reality: understanding the buried landscape through new techniques in field survey". En M. Bernardi (ed.): Archeologia del Paesaggio. IV Ciclo di Lezioni sulla Ricerca applicata in Archeologia, Certosa di Pontignano (Siena), 14-26 gennaio 1991. Quaderni del Dipartimento di Archeologia e Storia delle Arti, Sezione Archeologia, Università di Siena. Edizioni all' Insegna del Giglio. Florencia: 89-137.

Bintliff, J.L. 2000: "The concepts of site and offsite archaeology in surface artifact survey". En M. Pasquinucci y F. Trément (eds.): Non-destructive techniques applied to landscape archaeology. The Archaeology of Mediterranean Landscapes 4. Oxbow Books. Oxford: 200-215.

Bintliff, J.L. y Sbonias, K. (eds.) 1999: Reconstructing past population trends in Mediterranean Europe. The Archaeology of Mediterranean Landscapes 1. Oxbow Books. Oxford.

Bintliff, J.L. y Snodgrass, A.M. 1985: "The Cambridge/Bradford Boeotian expedition: the first four years". Journal of Field Archaeology 12: 123-161.

Bintliff, J.L. y Snodgrass, A.M. 1988: "Off-site pottery distributions: a regional and interregional perspective". Current Anthropology 29 (3): 506-513.

Brown, A.G. 1999: “Geomorphological techniques in Mediterranean Landscape Archaeology”. En P. Leveau, F. Trément, K. Walsh y G. Barker (eds.): Environmental reconstruction in Mediterranean Landscape Archaeology. The Archaeology of Mediterranean Landscapes 2, Oxbow Books. Oxford: 45-54.

Burillo, F. (ed.) 2006: Segeda y su contexto histórico: entre Catón y Nobilior (195 al 153). Homenaje a A. Beltrán Martínez. Estudios Celtibéricos 2, Centro de Estudios Celtibéricos de Segeda. Mara.

Carreté, J.M.; Keay, S. y Millet, M. 1995: A Roman provincial capital and its hinterland. The survey of the territory of Tarragona, Spain, 1985-1990. Journal of Roman Archaeology Supplement 15. Michigan.

Cherry, J.F. 1983: "Frogs round the pond: perspectives on current archaeological survey projects in the Mediterranean region". En D.R. Keller y W. Rupp (eds.): Archaeological survey in the Mediterranean area. British Archaeological Reports International Series 155. Oxford: 375-416.

Drennan, R.D. 1996: Statistics for archaeologists. A commonsense approach. Interdisciplinary Contributions in Archaeology. Plenum Press. Nueva York - Londres.

Drewett, P.L. 1999: Field archaeology. An introduction. UCL Press. Cornwall.

Fasham, P.J.; Schadla-Hall, R.T.; Shennan, S.J. y Bates, P.J. 1980: Fieldwalking for archaeologists. 
Hampshire Field Club and Archaeological Society. Winchester.

Fernández, V.M. y Lorrio, A.J. 1986: "Relaciones entre datos de superficie y del subsuelo en yacimientos arqueológicos: un caso práctico". Arqueología Espacial 7: 183-198.

Foley, R. 1981: "Off-site archaeology: an alternative approach for the short-sited". En I. Hodder, I. Glynn y N. Hammond (eds.): Pattern of the past. Studies in honour of David Clarke, Cambridge University Press. Cambridge: 157-183.

Francovich, R. y Patterson, H. (eds.) 2000: Extracting meaning from ploughsoil assemblages. The Archaeology of Mediterranean Landscapes 5, Oxbow Books. Oxford.

Gaffney, V.L.; Bintliff, J. y Slapsak, B. 1991: "Site formation processes and the Hvar Survey Project, Yugoslavia". En A.J. Schofield (ed.): Interpreting artefact scatters. Contributions to Ploughzone Archaeology. Oxbow Monograph 4, Oxbow Books. Oxford: 59-77.

Gallant, T.W. 1986: "Background noise and site definition. A contribution to survey methodology". Journal of Field Archaeology 13: 403-418.

García-García, F.; Castro, J.M.; Rey, J. y Ruiz Ortiz, P.A. 2003: "Sistemas de delta y plataforma en el Tortoniense del borde norte de la Cuenca del Guadalquivir (NE de Linares, provincia de Jaén)". Geotemas 5: 71-74.

García-Gelabert, M.P. 1988: "Restos de poblamiento en el área de influencia de Cástulo". En M.P. García-Gelabert y J.M. Blázquez: Cástulo, Jaén, España. I. Excavaciones en la necrópolis ibérica del Estacar de Robarinas (s. IV a.C.). British Archaeological Reports International Series 425. Oxford: 399-424.

García Sanjuán, L. 2005: Introducción al reconocimiento y análisis arqueológico del territorio. Ariel. Barcelona.

Gillings, M. y Sbonias, K. 1999: "Regional survey and GIS: the Boeotia Project". En M. Gillings, D. Mattingly y J. van Dalen (eds.): Geographical Information Systems and Landscapes Archaeology. The Archaeology of Mediterranean Landscapes 3, Oxbow Books. Oxford: 35-54.

Góngora, M. 1860: Viaje literario por las provincias de Granada y Jaén, Don Lope de Sosa, crónica mensual de la provincia de Jaén, año 1916, edición facsímil de 1982. Riquelme y Vargas. Jaén: 5-8 y 38-39.

Grau, I. 2006: La aplicación de los SIG en la arqueología del paisaje. Lucentum Anejo 15. Universidad de Alicante. Alicante.

Gutiérrez, L.M. 1998: "Roma y el poder local en el territorio del oppidum de Giribaile". En C. Aranegui (ed.): Los Iberos, Príncipes de Occidente: estructu- ras de poder en la sociedad ibérica. Saguntum Extra-1: 405-412.

Gutiérrez, L.M. 2002: El oppidum de Giribaile. Servicio de Publicaciones de la Universidad de Jaén. Jaén.

Gutiérrez, L.M.; Bellón, J.P. y Ceprián, B. 2007: “La Veguilla (Úbeda, Jaén). Prospección de superficie y caracterización del registro arqueológico". Actas del XXVI Congreso Nacional de Arqueología (Zaragoza 2001). Caesaraugusta 78: 781-791.

Gutiérrez, L.M.; Royo, M.A.; Bellón, J.P. y Barba, V. 1998: "Microprospección de superficie en el entorno del monumento". En M. Molinos, T. Chapa, A. Ruiz, J. Pereira, C. Rísquez, A. Madrigal, A. Esteban, V. Mayoral y M. Llorens (eds.): El santuario heroico de "El Pajarillo", Huelma (Jaén). Servicio de Publicaciones de la Universidad. Jaén: 161-215.

Haselgrove, C. 1985: "Inference from ploughsoil artefact samples". En C. Haselgrove, M. Millett e I. Smith (eds.): Archaeology from the ploughsoil. Studies in the collection and interpretation of field survey data, University of Sheffield. Sheffield: 7-29.

Hesse, A. 1971: "Tentative interpretation of the surface distribution of remains on the upper fort of Mirgissa (Sudanese Nubia). En F.R. Hodson, D.G. Kendall and P. Tautu (eds.): Mathematics in the archaeological and historical sciences. Aldine. Chicago: 436-444.

Hurtado, V. 2000: "Surface analysis of the copper age settlement of La Pijotilla (Spain)". En R. Francovich y H. Patterson (eds.): Extracting meaning from ploughsoil assemblages. The Archaeology of Mediterranean Landscapes 5, Oxbow Books. Oxford: 121-131.

Jones, R.F.J.; Blagg, T.F.C.; Devereux, C.M.; Jordan, D.W. y Millet, M. 1985: "Settlement, landscapes and survey archaeology in Catalunya". En S. Macready y F.H. Thompson (eds.): Archaeological field survey in Britain and abroad. The Society of Antiquaries of London, Occasional Paper (new series) VI. Londres: 116-128.

Keay, S. 1991: "Towns and territories" En G. Barker y J. Lloyd (eds.): Archaeological survey in the Mediterranean region. Archaeological Monographs of the British School at Rome 2. Oxford: 77-78.

Keay, S. y Millet, M. 1991: "Surface survey and site recognition in Spain: the Ager Tarraconensis survey and its background". En A.J. Schofield (ed.): Interpreting artefact scatters. Contributions to Ploughzone Archaeology. Oxbow Monograph 4, Oxbow Books. Oxford: 129-139.

Keay, S.; Remesal, J. y Creighton, J. 1993: "Proyecto: investigación arqueológica en la Viña de Peñaflor. La ciudad romano-turdetana de Celti (Peñaflor, Sevilla), Resumen de objetivos, actividades y meto- 
dología 1987-1992”. Investigaciones Arqueológicas en Andalucía 1985-1992, Proyectos, Huelva 1993. Dirección General de Bienes Culturales. Sevilla: 617-626.

Kirkby, A. y Kirkby, M.J. 1976: “Geomorphic processes and the surface survey of archaeological sites in semi-arid areas". En D.A. Davidson and M.L. Schackley (eds.): Geoarchaeology. Duckworth. Londres: 229-253.

Lewarch, D.E. y O'Brien, M.J. 1981: “The expanding role of surface assemblages in archaeological research". Advances in Archaeological Method and Theory 4: 297-342.

Lozano, G. y Gutiérrez, L.M. 2006: "Microprospección arqueológica de Cerro Alcalá (Torres, Jaén)". Anuario Arqueológico de Andalucía del año 2003 II: 266-272.

MacDonald, A. 1995: “All or Nothing at all? Criteria for the analysis of pottery from surface survey". En N. Christie (ed.): Settlement and economy in Italy 1500 B.C. to A.D. 1500. Papers of the Fifth Conference of Italian Archaeology. Oxbow Monograph 41. Oxford: 25-29.

Maluquer, J. 1976: "Panorama general de la problemática sobre el urbanismo prerromano en la Península Ibérica". Ciudades Augusteas de Hispania: Simposio celebrado con ocasión del bimilenario de la colonia Caesaraugusta. Departamento de Prehistoria y Arqueología de la Universidad de Zaragoza: 7-27.

Mattingly, D.J. y Coccia, S. 1995: "Survey methodology and the site: a Roman Villa from the Rieti survey". En N. Christie (ed.): Settlement and economy in Italy 1500 B.C. to A.D. 1500. Papers of the Fifth Conference of Italian Archaeology. Oxbow Monograph 41. Oxford: 31-44.

Mayoral, V.; Chapa, T. y Uriarte, A. 2004: "Recintos fortificados tardoibéricos en la región del Guadiana Menor: cuestiones de interpretación histórica y propuesta de nuevos métodos de estudio". En P. Moret y T. Chapa (eds.): Torres, atalayas y casas fortificadas. Explotación y control del territorio en Hispania (s. III a. de C. - s. I d. de C). Servicio de Publicaciones de la Universidad de Jaén - Casa Velázquez. Jaén: 97-118.

Millet, M. 2000a: "Dating, quantifying and utilizing pottery assemblages from surface survey". En R. Francovich y H. Patterson (eds.): Extracting meaning from ploughsoil assemblages. The Archaeology of Mediterranean Landscapes 5, Oxbow Books. Oxford: 53-59.

Millet, M. 2000b: "The comparison of surface and stratified artifact assemblages". En M. Pasquinucci y F. Trément (eds.): Non-destructive techniques applied to landscape archaeology. The Archaeology of Mediterranean Landscapes 4, Oxbow Books. Oxford: $216-222$.
Mills, N. 1985: "Iron Age settlement and society in Europe: contributions from field surveys in Central France". En S. Macready y F.H. Thompson (eds.): Archaeological field survey in Britain and abroad. The Society of Antiquaries of London, Occasional Paper (new series) VI. Londres: 74-100.

Orejas, A. 1996: Estructura social y territorio: el impacto romano en la cuenca noroccidental del Duero. Anejos de Archivo Español de Arqueología XV. Madrid.

Plog, S.; Plog, F. y Wait, W. 1978: "Decision making in modern surveys". En M.B. Schiffer (ed.), Advances in Archaeological Method and Theory. San Diego: 383-421.

Reid, J.J.; Schiffer, M.B. y Neff, J.M. 1975: “Archaeological considerations of intrasite sampling". En J.W. Mueller (ed.): Sampling in archaeology. The University of Arizona Press. Tucson: 209-224.

Renfrew, C. y Bahn, P. 1991: Archaeology. Theories, methods and practice. Thames and Hudson. Nueva York.

Ruiz Rodríguez, A.; Molinos, M.; Machado, R.; Egea, M.C. y Ortiz, S. 1990: "Prospección superficial en la cuenca del arroyo Salado de los Villares (Jaén)". Anuario Arqueológico de Andalucía de 1987 II. Sevilla: 139-147.

Ruiz Zapatero, G. 2004: “La prospección arqueológica de superficie en los inicios del siglo XXI". Arqueología Espacial 24-25: 17-32.

Salvatierra, V.; Castillo, J.C.; Portero, V.; Fernández, R.; Díaz, M.J. y Gómez, F. 2007: "La cerámica omeya de los silos de Geolit (Jaén). Un intento de reconstrucción cronológica de una secuencia horizontal no relacionada". En A. Malpica y J.C. Carvajal (ed.): Estudios de cerámica tardorromana y altomedieval. Salobreña: 107-133.

Schiffer, M.B.; Sullivan, A.P. y Klinger, T.C. 1978: "The design of archaeological surveys". World Archaeology 10 (1): 1-28.

Shennan, S.J. 1985: Experiments in the collection and analysis of archaeological survey data: the East Hampshire Survey. University of Sheffield. Sheffield.

Snodgrass, A.M. y Bintliff, J.L. 1991: “Arqueología sin excavación". Investigación y Ciencia 176: 67-73.

Stoddart, S.K.F. y Whitehead, N. 1991: "Cleaning the Iguvine stables: site and off-site analysis from a central Mediterranean perspective". En A.J. Schofield (ed.): Interpreting artefact scatters. Contributions to Ploughzone Archaeology. Oxbow Monograph 4, Oxbow Books. Oxford: 141-148.

Terrenato, N. 2004: "Sample size matters! The paradox of global trends and local surveys". En S.E. Alcock y J.F. Cherry (eds.): Side-by-side survey. Comparative regional studies in the Mediterranean world. Oxbow Books. Oxford: 36-48. 
Vermeulen, F. 2005: "The Potenza Valley Survey: first results of a long-term geo-archaeological project in marche". En P. Attema, A. Nijboer y A. Zifferero (eds.): Papers in Italian Archaeology VI: communities and settlements from the Neolithic to the early Medieval period. British Archaeological Reports International Series 1452 (II). Oxford: 984-992.

Walker, L. 1985: "Survey of a settlement: a strategy for the Etruscan site at Doganella in the Albegna valley". En C. Haselgrove, M. Millett y I. Smith (eds.): Archaeology from the ploughsoil. Studies in the collection and interpretation of field survey data, University of Sheffield. Sheffield: 87-94.

Wandsnider, L.A. 2004: “Artifact, landscape and temporality in Eastern Mediterranean archaeological landscape studies". En E. Athanassopoulos y L.A. Wandsnider (eds.): Mediterranean archaeological landscapes: current issues. University of Pennsyl- vania Museum of Archaeology and Anthropology. Philadelphia: 69-79.

Whallon, R. 1983: "Methods of controlled surface collection in archaeological survey". En D.R. Keller y W. Rupp (eds.): Archaeological survey in the Mediterranean area. British Archaeological Reports International Series155. Oxford: 73-83.

Wilkinson, T.J. 2004a: "The disjunction between Mediterranean and near Eastern survey. It is real?" En E. Athanassopoulos y L.A. Wandsnider (eds.): Mediterranean archaeological landscapes: current issues. University of Pennsylvania Museum of Archaeology and Anthropology. Philadelphia: 55-67.

Wilkinson, T.J. 2004b: "Surface collection techniques in field archaeology: theory and practice". En D.R. Brothwell y A.M. Pollard (eds.): Handbook of archaeological sciences. John Wiley et sons, ltd. Chichester - Nueva York - Weinheim - Brisbane - Singapore - Toronto: 529-541. 